\title{
Fundamentals of Methanol Synthesis on Metal Carbide Based Catalysts: Activation of $\mathrm{CO}_{2}$ and $\mathrm{H}_{2}$.
}

\author{
Sergio Posada-Pérez, ${ }^{a}$ Francesc Viñes, ${ }^{a}$ José A. Rodriguez, ${ }^{b}$ and
} Francesc Illas ${ }^{\mathrm{a},{ }^{*}}$

${ }^{a}$ Departament de Química Física \& Institut de Química Teòrica i Computacional (IQTCUB), Universitat de Barcelona, c/ Martí i Franquès 1, 08028 Barcelona, Spain.

${ }^{b}$ Chemistry Department, Brookhaven National Laboratory, Bldg. 555, Upton, NY 11973, USA.

*Corresponding author: francesc.illas@ub.edu

\begin{abstract}
$\mathrm{CO}_{2}$ hydrogenation to methanol and other alcohols constitutes an appealing route to recycle the large amount accumulated in the atmosphere through fossil-derived fuels burning. However, $\mathrm{CO}_{2}$ high chemical stability makes the overall process difficult and appropriate catalysts are needed. Transition metal carbides, either as active phase or as a support for noble metal clusters, have been shown to be able to activate $\mathrm{CO}_{2}$. Here, the mechanism involved in the decomposition of $\mathrm{H}_{2}$ and $\mathrm{CO}_{2}$ on many early transition metal carbides (TMC) surfaces is analyzed with the help of density functional theory (DFT) based calculations complemented by key experiments. Results show that $\mathrm{H}_{2}$ dissociation on $\mathrm{VC}$ and $\delta$ - $\mathrm{MoC}$ is unlikely, that $\mathrm{TiC}$ and $\mathrm{ZrC}$ are more reactive leading to an exothermic but activated process and that the $\mathrm{C}$ :Mo ratio is determinant factor since $\mathrm{H}_{2}$ dissociation on $\beta-\mathrm{Mo}_{2} \mathrm{C}(001)$ surface is even more exothermic. The DFT based calculations also show that $\mathrm{CO}_{2}$ adsorption on TMC results in an activated species with $\mathrm{TMC} \rightarrow \mathrm{CO}_{2}$ charge transfer, $\mathrm{C}-\mathrm{O}$ bond elongations and $\mathrm{OCO}$ bending. Supporting $\mathrm{Cu}_{4}$ and $\mathrm{Au}_{4}$ clusters on TMC(001) surfaces leads to more active catalysts due to the induced charge polarization. For $\mathrm{H}_{2}$ dissociation, $\mathrm{TiC}$ appears to be the best support, enhancing $\mathrm{H}_{2}$ both thermodynamics and kinetics. $\mathrm{CO}_{2}$ is strongly adsorbed on supported $\mathrm{Cu}_{4}$ and $\mathrm{Au}_{4}$ clusters, and the adsorption energy strength correlates with the methanol formation rate: $\mathrm{Cu}_{4} / \mathrm{TiC}(001)>\mathrm{Au}_{4} / \mathrm{TiC}(001)>$ $\mathrm{Cu} / \mathrm{ZnO}(001) \gg \mathrm{Cu}(111)$, thus providing potential alternative catalysts for methanol synthesis, in principle dozens of times better than commercial $\mathrm{Cu} / \mathrm{ZnO}$ based catalysts.
\end{abstract}

Keywords: Density Functional Calculations $\bullet$ Metal Carbides $\bullet \mathrm{CO}_{2}$ Activation $\bullet \mathrm{H}_{2}$ Dissociation - Methanol Synthesis 


\section{Introduction}

Among all pollutant gases in the earth atmosphere, carbon dioxide $\left(\mathrm{CO}_{2}\right)$ plays a key role due to its greenhouse gas effect. The exceedingly large $\mathrm{CO} 2$ concentration has been traced mostly to vast emissions of human origin through combustion of carbonaceous fuels, principally wood, coal, oil, and natural gas. ${ }^{1}$ The predictions indicate that $\mathrm{CO}_{2}$ emissions will continue to increase in $2040^{2}$ with devastating consequences in the so called global climate change. Therefore, the capture and conversion of $\mathrm{CO}_{2}$ into useful chemical should be a priority task.

In the past few years, $\mathrm{CO}_{2}$ chemistry has become a very attractive area of research, not only because of the environmental concerns mentioned above but also due to the potential use of $\mathrm{CO}_{2}$ as an alternative and economical $\mathrm{C}_{1}$ feedstock. ${ }^{3-5}$ Recycling $\mathrm{CO}_{2}$ gas through hydrogenation to methanol $\left(\mathrm{CO}_{2}+3 \mathrm{H}_{2} \rightarrow \mathrm{CH}_{3} \mathrm{OH}+\mathrm{H}_{2} \mathrm{O}\right)$ and higher alcohols or through decomposition to $\mathrm{CO}$ through the reverse water gas shift reaction $\left(\mathrm{CO}_{2}+\mathrm{H}_{2} \rightarrow \mathrm{CO}+\mathrm{H}_{2} \mathrm{O}\right)$ are appealing and probably economically viable since methanol can be directly used as a fuel and $\mathrm{CO}$ can be post-processed in syngas (a $\mathrm{CO}: \mathrm{H}_{2}$ mixture) reactions. These, in principal simple, processes may have important implications in the chemical industry, geopolitics, and carbon reuse in a sustainable Earth ecosystem. ${ }^{4,5} \mathrm{CO}_{2}$ usage is, nonetheless, cumbersome due to the challenges associated to the high chemical stability and concomitant difficult activation of this compound. ${ }^{6}$ Hence, chemical conversion of the extremely inert $\mathrm{CO}_{2}$ molecules typically involves a sequestration by a scrubber material, which either removes it permanently from the atmosphere, as in the case of geological reservoirs $^{7}$ or even in some ordinary shellfish, or ideally activates it altogether allowing for a sustainable recycling. The latter generally implies a catalyst which activates $\mathrm{CO}_{2}$ through a charge transfer mechanism leading to a highly bent adsorbed molecule. This can be achieved, for instance, through co-adsorption with an alkali metal on a metal surface, ${ }^{8,9}$ or the catalytic activation by transition metal catalysts with multiple redox states. ${ }^{10}$

Most of the catalysts used in the industry for the above-mentioned reactions use metal nanoparticles such as $\mathrm{Ni}, \mathrm{Pd}$, or Pt as an active phase supported either on oxides or sulfides. ${ }^{11}$ In the particular case of methanol synthesis through direct $\mathrm{CO}_{2}$ hydrogenation $\left(\mathrm{CO}_{2}+3 \mathrm{H}_{2} \rightarrow\right.$ $\mathrm{CH}_{3} \mathrm{OH}+\mathrm{H}_{2} \mathrm{O}$ ), a significant amount of work has been directed to find appropriate oxide-

supported metal catalysts. ${ }^{12-14}$ Indeed, commercially methanol is synthesized from syngas over $\mathrm{Cu}-\mathrm{ZnO} / \mathrm{Al}_{2} \mathrm{O}_{3}$ catalyst in a 493-573 $\mathrm{K}$ temperature range and with a gas pressure of 5-10 
$\mathrm{MPa}^{4,15}$ Under industrial operation conditions, isotope labeling experiments have shown that $\mathrm{CO}_{2}$ is the main carbon source for methanol. ${ }^{16}$ Due to the inherent catalyst complexity and also the high costs of the metal active phases, laboratory research experiments are commonly performed using model catalysts with metallic nanoparticles supported on well-defined oxide surfaces. ${ }^{17-19}$ In the current search for new catalysts, ${ }^{20}$ transition metal carbides (TMCs) have becomean appealing alternative, especially since recent experiments show that small $\mathrm{Cu}, \mathrm{Au}$, and Ni particles supported on $\mathrm{TiC}(001)$ surface display a catalytic activity for methanol synthesis orders of magnitude higher than conventional $\mathrm{Cu} / \mathrm{ZnO}$ catalyst, ${ }^{21,22}$ and even carbides can catalyze the reaction per se, as recently found for a $\beta-\mathrm{Mo}_{2} \mathrm{C}(001)$ surface with molybdenum termination. ${ }^{23}$

The other side of the coin in methanol synthesis implies $\mathrm{H}_{2}$ usage and, hence, adsorption and dissociation themselves become key processes to control in industry. It is worth pointing out that catalytic hydrogenation reactions are among the largest-volume human-made chemical processes worldwide. ${ }^{24}$ In the petrochemical industry, $\mathrm{H}_{2}$ is applied to all crude oil to remove sulfur, nitrogen, and oxygen traces. ${ }^{25}$ Moreover, hydrogenation of unsaturated carbon bonds is a key step in the production of fuels, fabrics, construction materials, and edible products. ${ }^{26}$ Finally, hundreds of million tons of ammonia fertilizer are produced annually from $\mathrm{H}_{2}$ and $\mathrm{N}_{2}$ by the well-known Haber process, helping to provide enough food to the world population. $\frac{24,26}{r}$ The hydrogen molecule is also quite stable because of the strong covalent single bond, and is chemically useful only when the two hydrogen atoms can be split apart in a controlled way $\frac{24-26}{4}$ Again, the most common components of heterogeneous catalysts industrially used for $\mathrm{H}_{2}$ splitting are in the form of transition metal nanoparticles supported on oxides or sulfides. ${ }^{27-29}$ Recently it was found that small gold clusters in contact with $\mathrm{TiC}(001)$ surface exhibited a very high catalytic activity for the hydrogenation of thiophene, ${ }^{30,31}$ pointing for a reduction of the activation energy compared to that on pristine $\mathrm{TiC}(001)$ surface or on $\mathrm{Au}$ systems even when containing low coordinated sites. ${ }^{32}$ These works strongly suggest that a strong metal $\leftrightarrow$ carbide interaction is responsible of the enhanced activity. ${ }^{33}$

In this article, we review a series of studies which examine the interaction of $\mathrm{CO}_{2}$ and $\mathrm{H}_{2}$ molecules with metal-carbide surfaces at a fundamental level, in relationship to methanol synthesis and also provide new results regarding $\mathrm{H}_{2}$ dissociation on $\mathrm{MoC}$ and $\mathrm{Mo}_{2} \mathrm{C}$. In this line, 
and in order to improve TMC catalytic performance, either as active phase or as a (non-innocent) support, one must unveil $(i)$ whether, and how, the chemical reactivity is modified by the metal/carbon ratio, (ii) the importance of ensemble and ligand effects, i.e. whether surface carbon atoms do play a role or are mere spectators, (iii) the effect of covalent bonding with the carbide substrate in $\mathrm{CO}_{2}$ adsorption, and of final states for $\mathrm{H}_{2}$ and $\mathrm{CO}_{2}$ splitting and, in the case of metal nanoparticles supported on TMC, (iv) the accommodation of small metal clusters on TMC surfaces and their effect on the metal electron density depending on the nature of the metal $\leftrightarrow$ carbide interface, and their implications on $\mathrm{CO}_{2}$ activation and $\mathrm{H}_{2}$ splitting on these carbide-supported catalysts.

TMCs exhibit broad and amazing physical and chemical properties that, in many aspects, are very similar to those of expensive noble metals such as $\mathrm{Pt}$ or $\mathrm{Rh}$ commonly used in catalysis. $^{34,35}$ Typically parent early transition metals are very reactive and attach adsorbates too strongly to be useful in catalysis ( $c f$. the well-known Le Sabatier's principle). ${ }^{36}$ The inclusion of $\mathrm{C}$ in their crystal lattice produces a substantial gain in stability, ${ }^{37}$ and moderates the chemical activity of the resulting material through both ensemble and ligand effects: the presence of carbon atoms limits the number of surface metal atoms exposed (ensemble effect) and the formation of carbon-metal bonds modifies the electronic structure, normally reducing the number of states at Fermi level, making it less active (ligand effect), and, consequently, a better catalyst, again this is consistent with the main ideas of the Le Sabatier's principle as shown in previous work by some of the authors. ${ }^{33}$ In addition TMCs display a unique combination of properties characteristic of covalent solids, ionic crystals, and transition metals, such as good electrical and thermal conductivities, ultra-hardness, and very high melting points, which stem out from the chemical bonding within their electronic structure. ${ }^{38}$ Because of these properties and their low cost, TMCs have become a type of materials with an increasing role in various applications in materials science $\frac{34}{\Delta}$ but also as potential alternative systems in heterogeneous catalysis as shown in a series of model systems and for a variety of technologically relevant chemical reactions by combination of experiments under controlled conditions and DFT based calculations on realistic models. $^{39-404142}$

The article is organized as follows. The next section gives a summary of the theoretical methods and experiments performed in the studies commented above. Then, we focus on the description of the adsorption and dissociation of $\mathrm{H}_{2}$ on surfaces of various metal carbides. This is 
followed by recent work focusing on the interaction of $\mathrm{CO}_{2}$ with the most stable surfaces of various $\mathrm{TMC}$ such as $\mathrm{TiC}, \mathrm{WC}, \mathrm{MoC}$ and $\mathrm{Mo}_{2} \mathrm{C}$, tungsten, and molybdenum carbide surfaces. Next we examine the reactivity metal clusters supported on TMC towards $\mathrm{H}_{2}$ dissociation with the ultimate goal of determining the best carbide, or carbide/metal cluster combination towards this important reaction. Finally best candidates are used to explore $\mathrm{CO}_{2}$ activation and hydrogenation, providing a detailed description of the molecular mechanism which allows unraveling the origin of excellent performance of these systems and why some of them exhibit a catalytic activity higher than the commercial $\mathrm{Cu} / \mathrm{ZnO}-\mathrm{Al}_{2} \mathrm{O}_{3}$ catalyst used in methanol synthesis industrial plants.

\section{Theoretical and Experimental Methods}

\subsection{Computational Details}

Periodic Density Functional Theory (DFT) based calculations have been carried out using the Vienna $A b$ initio Simulation Package $(V A S P)^{43}$ or the DMol ${ }^{3}$ package. ${ }^{44}$ Exchangecorrelation effects have been accounted for by means of the Generalized Gradient Approximation (GGA) using most often the Perdew-Burke-Ernzerhof (PBE) exchangecorrelation $(x c)$ functional, ${ }^{45}$ but also similar but slightly different forms such as the revised PBE $(R P B E),{ }^{46}$ or well-known Perdew-Wang (PW91) implementation. ${ }^{47}$ These $\mathrm{xc}$ functionals are suited for the description of bulk and surfaces of all the studied TMCs, ${ }^{38,48}$ and transition metals in general. ${ }^{49}$

In the calculations with the VASP code, a plane-wave basis set with a cut-off kinetic energy of $415 \mathrm{eV}$ was used to expand the valence electron density, whereas for $\mathrm{DMol}^{3}$ calculations a numerical basis set with accuracy comparable to Gaussian G-31G (d) basis set was employed. In plane-wave calculations the effect of the atomic cores on the valence electron density has been taken into account by means of the projected augmented wave method of Blöch. ${ }^{50}$ Monkhorst-Pack schemes ${ }^{51}$ of different optimal densities were used to select the special k-points when carrying out the numerical integrations in the reciprocal space, keeping the density proportional in bulk and slab calculations $\frac{38,48}{r}$ The atomic (ionic cores) relaxation convergence criterion was adjusted so that all forces acting on atoms were always better than $0.03 \mathrm{eV} \AA^{-1}$, with an electronic relaxation criterion better than $0.001 \mathrm{eV}$. 
Slabs of four (three) atomic layers were always employed when carrying out VASP $\left(\mathrm{DMol}^{3}\right)$ calculations, in which the two (one) uppermost layers were fully allowed to relax during optimizations, together with the adsorbate and/or the supported metal cluster. In the supercells a minimum vacuum of $10 \AA$ was added to avoid interactions between repeated slabs. Adsorption of metal adatoms, metal clusters, $\mathrm{H}_{2}$ or $\mathrm{CO}_{2}$ molecules was studied on the relaxed slab surface. The adsorption energy $\left(E_{a d s}\right)$ of a moiety $A$ has been calculated according to the following formula:

$$
E_{a d s}=E_{A / S l a b}-\left(E_{\text {Slab }}+E_{A}\right)
$$

where $E_{A / S l a b}$ is the energy of $A$ adsorbed/attached on the corresponding slab surface; $E_{\text {Slab }}$ is the energy of the pristine and relaxed slab surface; and $E_{A}$ is the energy of the isolated $A$ moiety in an asymmetric box of $9 \times 10 \times 11 \AA$ dimensions. Note that for the adsorption of molecules on carbide-supported metal clusters, $E_{\text {Slab }}$ refers to the relaxed surface with the attached cluster. Within this notation, the more negative the Eads value, the stronger the interaction.

For polar surfaces with different terminations a counterdipole was placed in the middle of the vacuum region to avoid dipole coupling between repeated slabs. When necessary van der Waals $(v d W)$ corrections were accounted for following the Grimme ${ }^{52}$ scheme. The electronic structure has been analyzed through a topological analysis of the Electron Localization Function $(E L F)^{53}$ and charge distributions were estimated by the Atoms in Molecules topological analysis of the electron density method of Bader. ${ }^{54}$ The localization of transition states for $\mathrm{H}_{2}$ scission and $\mathrm{CO}_{2}$ dissociation was carried out in either a stepwise fashion, or with the help of the Climbing Image Nudged Elastic Band $(C I-N E B) .{ }^{55,56}$ Minima and transition sates were afterwards properly characterized by explicit diagonalization of the Hessian matrix, i.e. vibrational analysis. For further details we refer to the literature.

\subsection{Experimental Studies}

The $\mathrm{TiC}(001)$ surface of single crystal was cleaned following methodologies reported in the literature. ${ }^{57,58}$ The $\delta$-MoC was used in a polycrystalline form, whereas Mo-terminated $\beta$ $\mathrm{Mo}_{2} \mathrm{C}(001)$ surface was cleaned and prepared by ion bombardment and subsequent annealing at $1000 \mathrm{~K} .{ }^{59}$ Several attempts were made to prepare well-defined surfaces of $\delta$-MoC oriented along the (001) plane of this carbide. However, it was not possible to prepare an ideal $\delta$-MoC(001) surface. The preparation of this particular surface is very difficult due to the complex phase 
diagram of MoC. ${ }^{60}$ Metallic $\mathrm{Cu}$ or Au clusters were vapor-deposited on the samples at $300 \mathrm{~K}$. The admetal dosers consisted of a resistively heated $\mathrm{W}$ basket with a drop of ultrapure $\mathrm{Au}$ or $\mathrm{Cu}$ inside. $\frac{57,61}{r}$ Initially the flux of each doser was calibrated by taking thermal desorption spectra of $\mathrm{Au}, \mathrm{Cu}$, or Ni from a Mo(100) substrate $\frac{57,62}{\mathrm{~V}}$ This information was then used to calibrate admetal coverage estimated by means of X-ray Photoelectron Spectroscopy (XPS).

The systems were studied in a set-up that combines a Ultra-High Vacuum (UHV) chamber for surface characterization (base pressure $\sim 5 \times 10^{-10}$ Torr) and a batch reactor for catalytic tests. ${ }^{22,63,64}$ The sample could be transferred between the reactor and the UHV chamber without exposure to air. The UHV chamber was equipped with instrumentation for XPS and Ultraviolet Photoelectron Spectroscopy (UPS), Low-Energy Electron Diffraction (LEED), IonScattering Spectroscopy (ISS), Temperature Programmed Desorption (TPD), and ThermalDesorption mass Spectroscopy $(T D S) \cdot \frac{63}{\mathrm{~V}}$

In the studies of $\mathrm{CO}_{2}$ hydrogenation, the sample was transferred to the reactor at $\sim 300 \mathrm{~K}$, then the reactant gases, $0.049 \mathrm{MPa}(0.5 \mathrm{~atm})$ of $\mathrm{CO}_{2}$ and $0.441 \mathrm{MPa}(4.5 \mathrm{~atm})$ of $\mathrm{H}_{2}$, were introduced and the sample was rapidly heated to the reaction temperature $(500,525,550,575$ and $600 \mathrm{~K}) \cdot \frac{64}{4}$ Product yields were analyzed by a mass spectrometer and/or a gas chromatograph $\frac{13}{v}$ The amount of molecules $\left(\mathrm{CO}, \mathrm{CH}_{4}\right.$, or $\left.\mathrm{CH}_{3} \mathrm{OH}\right)$ produced in the catalytic tests was normalized by the active area exposed by the sample and the total reaction time. In the present experiments, data were collected at intervals of $15 \mathrm{~min}$ up to total reaction times of 270 min. The kinetic experiments were done in the limit of low conversion $(<5 \%)$. Note that in the case of the reverse water-gas shift, simultaneous production of $\mathrm{CO}$ and water is observed, but, for simplicity, only CO production is reported as typically done is these studies. ${ }^{65}$

\section{Results and Discussion}

\section{1. $\mathrm{H}_{2}$ Splitting on TMC(001) Surfaces}

$\mathrm{H}_{2}$ dissociation is an essential step in any catalytic cycle involving hydrogenation reactions; in particular for $\mathrm{CO}_{2}$ hydrogenation to methanol or higher alcohols. In a pioneering work, Levy and Boudart ${ }^{66}$ found that that tungsten carbide (WC) exhibited a catalytic activity towards hydrogenation reactions similar or even better than that of platinum. However, the reasons for the high activity, clearly associated to the capability to facilitate $\mathrm{H}_{2}$ dissociation remained unclear. In a first theoretical study focusing on the molecular mechanism of the water 
gas shift reaction on $\mathrm{TiC}$ nanostructures and on the extended $\mathrm{TiC}(001)$ surface, a quite small value $(0.05 \mathrm{eV})$ was predicted for the $\mathrm{H}_{2}$ adsorption energy on $\mathrm{TiC}(001) \cdot{ }^{67}$ This weak interaction seems to contradict the findings of Levy and Boudart on WC since molecular hydrogen adsorbed on $\mathrm{TiC}(001)$ will likely desorb before desorbing. Additional work using a large $3 \times 3$ supercell revealed that the molecule prefers to bind on top of a surface $\mathrm{C}$ atom with the $\mathrm{H}_{2}$ aligned towards vicinal surface $\mathrm{C}$ atoms (Figure 1) and with a strong interaction leading to a calculated value of $0.48 \mathrm{eV}$ for the adsorption energy (see Table 1). ${ }^{68}$ The reason to comment this point in some detail is to illustrate the need to use realistic models and, whenever possible, to check against experimental data. The difference between the two model calculations commented above can be traced to the supercell size, a small $(\sqrt{2} \times \sqrt{2}) \mathrm{R} 45^{\circ}$ cell was employed in the study of the water gas shift reaction leading to a too strong steric repulsion between adsorbates, and a concomitant decreased adsorption energy. The situation modeled in this way corresponds to an excessive coverage of hydrogen on the surface. This does not affect the main conclusions regarding the mechanism of the water gas shift reaction on TiC systems (see below) but leads to an unrealistic description of $\mathrm{H}_{2}$ adsorption/desorption. Interestingly, the effect of the model on the situation corresponding to the dissociated molecule is much less important, it described in a similar way by the $(\sqrt{ } 2 \times \sqrt{ } 2) R 45^{\circ}$ and $3 \times 3$ supercells with calculated reaction exothermicity values of -0.30 and $-0.43 \mathrm{eV}$, respectively. Concerning the dissociation path and its associated energy barrier, an homolytic dissociation in which the two formed $\mathrm{H}$ atoms move to occupy vicinal positions was initially investigataed, but the associated energy barrier of $1.14 \mathrm{eV}$ (predicted with the more extended $3 \times 3$ supercell) was clearly noncompetitive with respect to an alternative path in which only one $\mathrm{H}$ displaces to a vicinal surface $\mathrm{C}$ atom, while the other remains at the on-top position. The calculated energy barrier values for this alternative mechanism are $0.52 \mathrm{eV}$ or 0.60 depending on whether the $(\sqrt{ } 2 \times \sqrt{ } 2) \mathrm{R} 45^{\circ}$ or $3 \times 3$ supercell is used. ${ }^{67,68}$ Here, as in the case of the reaction products (separated adsorbed $\mathrm{H}$ atoms), the two surface models lead to consistent results. However, this is not the case for the reactants (adsorbed $\mathrm{H}_{2}$ ). Note also that the small energy barriers are consistent with the experimental observation of $\mathrm{H}-\mathrm{H}$ bond cleavage upon adsorption on $\operatorname{TiC}(001)$ at room temperature $\frac{30,69}{\frac{r}{r}}$

From the discussion above it is already clear that surface $\mathrm{C}$ atoms, at least for $\mathrm{TiC}(001)$, are not pure spectators, but crucial sites in the $\mathrm{H}_{2}$ dissociation mechanism and questions the use of ligand and ensemble concepts in the surface chemistry of transition meta carbides. 
Furthermore, the exothermicity is governed by the high stability of covalent $\mathrm{C}-\mathrm{H}$ bonds formed on the surface. To further investigate this effect, $\mathrm{H}_{2}$ dissociation on $\mathrm{ZrC}(001), \mathrm{VC}(001)$, and $\delta$ $\mathrm{MoC}(001)$ surfaces was studied in detail. ${ }^{70}$ Here we will also comment on new results corresponding to the Mo and $\mathrm{C}$ terminations of $\beta-\mathrm{Mo}_{2} \mathrm{C}(001)$ surface. These have been recently predicted to be among the most stable endings of orthorhombic $\beta-\mathrm{Mo}_{2} \mathrm{C} \cdot \frac{48}{\mathrm{r}} \mathrm{Here}$, the idea is to determine whether $\mathrm{H}_{2}$ splitting is more or less favored by a given TMC. From the thermodynamic and kinetic results encompassed in Table 1, it is clear that there is no general trend for carbides. However, $\mathrm{H}_{2}$ adsorption on $\mathrm{TiC}(001)$ and $\mathrm{ZrC}(001)$ lead to similar adsorption energy values and, in both cases, dissociation is exothermic although slightly more for the latter. This is in line with similar chemical activity of group IV carbides towards $\mathrm{O}_{2}$ dissociation. ${ }^{71,72}$ In the final (dissociated molecule) state there is strong interaction between the adsorbed $\mathrm{H}$ atoms and the underlying TMC surface, which is evidenced by vibrational frequencies of $\sim 650 \mathrm{~cm}^{-1}$ and $\sim 2800 \mathrm{~cm}^{-1}$ for horizontal frustrated translation and $\mathrm{H}$ adatom displacement perpendicular to the surface (C-H stretching). Despite the similitudes in adsorption and reaction energy, the $\mathrm{H}_{2}$ dissociation energy barrier on $\mathrm{ZrC}(0.80 \mathrm{eV})$ is noticeable larger than on $\mathrm{TiC}(0.52 \mathrm{eV})$ posing the former as a more inert support, despite the transition state is just slightly above $(0.14 \mathrm{eV})$ the energy of the non-interacting systems with $\mathrm{H}_{2}$ far away from the carbide surface.

The situation for $\mathrm{H}_{2}$ on $\mathrm{VC}(001)$ and $\delta$-MoC $(001)$ surfaces is quite different and deserves a separate discussion. Here the DFT periodic calculations with the PW91 functional predict an essentially null adsorption energy. Moreover, the dissociated state energy may lie above the reference of the separated systems which is the case for VC. On these two surfaces, $\mathrm{H}_{2}$ dissociation is unlikely, the geometry optimization for the dissociated state shows a strong deformation of the surface which eventually leads to the extraction of surface $\mathrm{C}$ atoms and the formation of $\mathrm{CH}$ entities, with a concomitant etching of the underlying substrate, see Figure 2. The weak interaction of $\mathrm{H}_{2}$ with $\mathrm{VC}$ and $\delta$ - $\mathrm{MoC}$ and the too strong interaction with $\mathrm{H}$ atoms seems not to be compatible with the stability properties required for a good support in catalysis. The weak interaction predicted by the PW91 functional may become noticeable when vdW forces are explicitly included. To investigate the influence of dispersion terms, at least in of the cases, new DFT based calculations have been carried with the PBE functional including or not $v d W$ for the case of $\mathrm{H}_{2}$ on the $\delta$ - $\mathrm{MoC}(001)$ surface. The adsorption site of $\mathrm{H}_{2}$ on $\delta-\mathrm{MoC}(001)$ 
still is on-top of a surface $\mathrm{C}$ atom, although now molecule is slightly tilted towards the surface. No special activation of the adsorbed molecule is observed, with molecular bond lengths of 0.75 and $0.77 \AA$ for PBE and PBE-vdW, respectively, and thus very close to the calculated value for the molecule in vacuum $(0.74 \AA)$. However, the $\mathrm{H}_{2}$ adsorption energy is considerably enhanced and values of -0.45 to $-0.75 \mathrm{eV}$ are predicted by PBE and PBE-vdW, respectively. Indeed, the dissociated state presents adsorption energy values larger than $-1 \mathrm{eV}$, similar to group IV TMCs. The discrepancy between results predicted by the PW91 and PBE functionals is difficult to understand since these functionals usually exhibit a similar trend ${ }^{49}$ and since the PBE reaction exothermicity remains similar to the one predicted by PW91. In spite of the discrepancy in the adsortion energy of the hydrogen molecule, the same qualitative description emerges regardless of the computational level used.

From the previous discussion it appears that the inclusion of vdW forces is not affecting the thermodynamics of $\mathrm{H}_{2}$ dissociation on the $\delta$-MoC $(001)$ surface. This finding is further supported by the results obtained on polar Mo- and $\mathrm{C}$-terminated $\beta-\mathrm{Mo}_{2} \mathrm{C}(001)$ surfaces. The addition of dispersive forces may sensibly lower the adsorption energies for molecular and dissociated $\mathrm{H}_{2}$, but the reaction energy changes at most $\pm 0.1 \mathrm{eV}$, this is, within DF standard accuracy. In these polar surfaces it is worth to note that adsorption energy is essentially cero for C-termination, despite the fact that the dissociated state is highly stable, due to the saturation by $\mathrm{CH}$ bond formation of unsaturated surface $\mathrm{C}$ atoms. Indeed the exothermicity of the reaction can be larger than $-2.3 \mathrm{eV}$ which facilitates a rapid and easy dissociation of $\mathrm{H}_{2}$. However, the quite small adsorption energy of molecular hydrogen can hinder the process with desorption occurring prior dissociation at the surface. In the case of Mo-termination, the adsorption energy of $\mathrm{H}_{2}$ is larger than $\sim-0.8 \mathrm{eV}$, and the scission exothermicity is of $-1.21 \mathrm{eV}$. This last results highlights the relevance of the C:Mo ratio which can be a determining factor for $\mathrm{H}_{2}$ dissociation; Moterminated $\beta-\mathrm{Mo}_{2} \mathrm{C}(001)$ can capture and dissociate $\mathrm{H}_{2}$ easier than $\delta$-MoC $(001)$ surface even without forming $\mathrm{CH}$ covalent bonds. However, such comparison cannot be put apart from the existence of surface $\mathrm{C}$ atoms as a hindering factor. In any case, (001) surfaces of $\mathrm{TiC}, \mathrm{ZrC}$, and even $\delta$-MoC are able to dissociate $\mathrm{H}_{2}$, yet the highest activity is envisaged for Mo-terminated $\beta$ $\mathrm{Mo}_{2} \mathrm{C}(001)$ surface. $\mathrm{VC}(001)$ surface is apparently pretty resilient to hydrogenation, a fact that may add a layer of versatility when choosing one or another carbide as a substrate. 


\section{2. $\mathrm{CO}_{2}$ Sequestration, Activation and Dissociation on TMC(001) Surfaces}

Tominaga and Nagai were among the first to use theoretical chemistry to study the interaction of $\mathrm{CO}_{2}$ and transition metal carbides. ${ }^{73}$ These authors carried out DF calculations with the hybrid Becke-Lee-Yang-Parr $(B 3 L Y P)$ xc functional, including Effective Core Potentials $(E C P)$ and the Dunning-Huzinaga full double- $\zeta$ (D95) basis set. However, they used quite limited size cluster models $\left(\mathrm{Mo}_{4}\right.$ and $\left.\mathrm{Mo}_{4} \mathrm{C}_{2}\right)$ to simulate the Mo and $\mathrm{Mo}_{2} \mathrm{C}$ surfaces. This choice probably hinders accurate predictions of the properties of interest although their study sets the basis for a first comparison. The B3LYP cluster model calculations of Tominaga and Nagai already predict that $\mathrm{CO}_{2}$ adopts a bent conformation on both systems with a $\mathrm{O}-\mathrm{C}-\mathrm{O}$ molecular angle of $134^{\circ}$. However, the adsorption energy on the carbide cluster $(-2.20 \mathrm{eV})$ is sensibly higher than on the Mo one $(-1.40 \mathrm{eV})$. At first sight this may seem a counterintuitive finding since by ligand and ensemble effects one would expect a decreased activity of the carbide cluster compared to the metallic one. The difference can be safely attributed to size effects such as quantum confinement, which usually enhances the chemical activity of small clusters with respect to the extended surface of the same material. For instance, the calculated adsorption energy values for $\mathrm{CO}_{2}$ on $\mathrm{Mo}_{4}$ and $\mathrm{Mo}_{4} \mathrm{C}_{2}$ are comparable to the values for $\mathrm{CO}_{2}$ adsorption on $\mathrm{Ti}_{8} \mathrm{C}_{12}$ MetCar and $\mathrm{Ti}_{14} \mathrm{C}_{13}$ Nanocrystal ( -1.77 and $-2.56 \mathrm{eV}$, respectively) predicted by the PW91 functional. $\frac{67}{\Delta}$ Only when dealing with sufficiently large clusters are the calculated adsorption energy values comparable to those corresponding to the extended surfaces, as found for metal compounds. ${ }^{74}$ Note, however, that the molecular structure of the adsorbed molecule is less dependent on the cluster model size.

From the previous discussion it is clear that the interaction of $\mathrm{CO}_{2}$ with extended TMC surfaces will be significantly different than for small TMC clusters. In fact, $\mathrm{CO}_{2}$ is found to adsorb quite weakly on the $\mathrm{TiC}(001)$ surface, with an adsorption energy of $-0.22 \mathrm{eV}$ only although already adopting a bent conformation where the $\mathrm{O}$ atoms interact directly with a surface

Ti atom and the $\mathrm{C}$ atom interacts with a surface $\mathrm{C}$ atom, see Table $2 \cdot \frac{67}{\Delta}$ The small value of the adsorption energy, in the range of physisorption, does not mean that the interaction is mainly due to dispersive forces. The large distortion of the adsorbed $\mathrm{CO}_{2}$ molecule arises from a carbide $\rightarrow$ molecule charge transfer. The energy cost for molecular deformation is compensated by an interaction of similar magnitude with the surface, including columbic attraction between 
positively charge surface $\mathrm{Ti}$ atoms and molecule $\mathrm{O}$ atoms with increased electron density, plus a likely covalent C-C bond formation. Additional PW91 calculations using larger supercells (smaller coverage) pointed to the same adsorption conformation with increased attachment strength to a value of $-0.62 \mathrm{eV}$, see Figure 3 . This implies a strong $\mathrm{C}-\mathrm{C}$ bond with a length of $1.48 \AA$, and two weak Ti-O bonds with Ti-O distance of $2.24 \AA$. Note that on the TiC $(001)$ surface, the complete dissociation of the $\mathrm{CO}_{2}$ molecule is essentially isoenergetic, and the $\mathrm{CO}$ dissociation endothermic by $\sim 1.65 \mathrm{eV}$. This is argued to be a key point for methane formation prevention on $\mathrm{TiC}(001)$, at variance with $\mathrm{Mo}_{2} \mathrm{C}$ and $\mathrm{Fe}_{3} \mathrm{C}$, ${ }^{75}$ where $\mathrm{CH}_{4}$ formation is observed.

The simultaneous $\mathrm{C} \leftrightarrow \mathrm{C}$ and metal $\leftrightarrow \mathrm{O}$ interactions seem to be a rule of a thumb in this type of systems where both metal and carbon surface atoms are (almost) available. In fact, recent DF calculations by $\mathrm{Wu}$ and $\mathrm{Ho}$ at the PW91 level revealed that when $\mathrm{CO}_{2}$ adsorbs on the WC(001) W-terminated surface, the preferred geometry involves the two $\mathrm{O}$ atoms pointing towards two different neighboring $\mathrm{W}$ atoms, whereas the $\mathrm{C}$ atom is placed above a subsurface $\mathrm{C}$ atom forcing a molecular bending of the OCO angle up to $121^{\circ} .^{76}$ The adsorption energy of -0.99 $\mathrm{eV}$ is of similar strength to the one found for $\mathrm{CO}_{2}$ on $\mathrm{TiC}(001)$. Here a strong charge transfer from the TiC substrate to $\mathrm{CO}_{2}$ of $\sim 1.56 \mathrm{e}$ is clearly the responsible for the molecular bending. This is also found for $\mathrm{CO}_{2}$ adsorption on $\delta$-MoC and $\beta-\mathrm{Mo}_{2} \mathrm{C}(001)$ surfaces, where, regardless of neglecting or explicitly including dispersion terms through a PBE-vdW scheme, $\mathrm{CO}_{2}$ receives a charge transfer of essentially $\sim 1$ electron. ${ }^{77}$ The inclusion of a term describing dispersive forces downloads systematically the adsorption energies by $\sim 0.4-0.6 \mathrm{eV}$ although structural parameters like bond lengths and molecular angles remain unaltered, and the relative stabilities are also preserved. Therefore, one can claim that vdW forces, even representing a significant contribution to the final calculated adsorption energy value, are not the key aspect fordescribing $\mathrm{CO}_{2}$ adsorption on molybdenum carbides, and therefore, same conclusions could be withdrawn neglecting these terms during geometry optimizations.

In spite of the fact that $\mathrm{CO}_{2}$ gets activated in any of the molybdenum carbide surfaces commented above with molecular angles close to $120^{\circ}$ and $\mathrm{C}-\mathrm{O}$ bond lengths increased to values ranging 1.21-1.42 $\AA$, a different situation emerges when the TMC surface exhibit exposed surface carbon as in the $\delta$-MoC(001) surface, and in C-terminated $\beta-\mathrm{Mo}_{2} \mathrm{C}(001)$ surface. In these cases, the interaction of $\mathrm{CO}_{2}$ with the TMC surface results in the creation of a new $\mathrm{C}-\mathrm{C}$ bond, 
with a rather constant bond length of $\sim 1.46 \AA$. Last but not least, it is worth pointing out that adsorption strengths, even when neglecting vdW terms, are always larger than $-0.6 \mathrm{eV}$ and thus in line with the values commented above for $\mathrm{CO}_{2}$ on WC and TiC (001) surfaces. Note that, even if these adsorption energy values cannot be considered as medium or large in magnitude, they largely exceed the small adsorption energy $(<-0.2 \mathrm{eV})$ found in experimental and theoretical studies for $\mathrm{CO}_{2}$ on $\mathrm{Cu}$ surfaces - the active phase on $\mathrm{Cu} / \mathrm{ZnO}$ methanol synthesis catalystwhere $\mathrm{CO}_{2}$ bond stays linear as in gas phase. ${ }^{4,64,78}$ Thus, TMC surfaces exhibit an enhanced ability to capture and activate $\mathrm{CO}_{2}$. This is clear from recent DF calculations with the PBE functional showing that complete $\mathrm{CO}_{2}$ dissociation on the Mo-terminated $\beta-\mathrm{Mo}_{2} \mathrm{C}(001)$ surface is exothermic by $-1.89 \mathrm{eV}$. This is in clear contrast to the case of $\mathrm{CO}_{2}$ on $\operatorname{TiC}(001)$ where this reactions is thermoneutral. This in principle explains the formation of $\mathrm{CH}_{4}$ when hydrogenating $\mathrm{CO}_{2}$ on $\mathrm{Mo}_{2} \mathrm{C}$, as observed in experiments. $\frac{75,77}{r}$ Indeed, $\mathrm{CO}$ and $\mathrm{CH}_{4}$ are the main products during methanol synthesis on Mo-terminated $\beta-\mathrm{Mo}_{2} \mathrm{C}(001)$ surface. Note that $\mathrm{CO}_{2}$ dissociation into $\mathrm{CO}+\mathrm{O}$ on Mo-terminated $\beta-\mathrm{Mo}_{2} \mathrm{C}(001)$ features a relative small barrier of $0.76 \mathrm{eV}$.The theoretical predictions are in excellent agreement with experiments. Figure 4 reports the intensity of $\mathrm{O} 1 \mathrm{~s}$ signal in XPS experiments due to formed $\mathrm{O}$ adatoms; the intensity increases proportionally to the $\mathrm{CO}_{2}$ dose at $300 \mathrm{~K}$, whereas is much hindered for polycrystalline $\delta$-MoC samples. Another recent DF study with the PBE functional revealed that CO dissociation was found to be exothermic, although overcoming energy barriers larger than $1 \mathrm{eV}{ }^{79}$ This goes with a range of low temperatures in which $\mathrm{CO}_{2}$ could be dissociated into $\mathrm{CO}+\mathrm{O}$ and where the formed $\mathrm{CO}$ molecules could be stable at the surface. However, at $300 \mathrm{~K}$, XPS experiments show that CO becomes also dissociated. Consequently, $\mathrm{CO}$ and $\mathrm{CH}_{4}$ are the main products when hydrogenating $\mathrm{CO}_{2}$ on Mo-terminated $\beta$-Mo $\mathrm{Mo}_{2} \mathrm{C}(001)$ surface. On $\delta$-MoC powder samples, $\mathrm{CO}_{2}$ dissociation is less likely than on $\beta-\mathrm{Mo}_{2} \mathrm{C}$, and this is also the case for $\mathrm{CO}$ dissociation. Therefore, selectivity on methanol synthesis is enhanced with $\mathrm{CO}$ and $\mathrm{CH}_{3} \mathrm{OH}$ as main products. The Arrhenius plots show an apparent activation energy for methanol synthesis of $0.75 \mathrm{eV}$ on polycrystalline $\delta-\mathrm{MoC}$, smaller than the corresponding values of 0.91 and $1.1 \mathrm{eV}$ found when the reaction takes place on $\mathrm{TiC}(001)$ and $\mathrm{Cu}(111)$, respectively $\frac{22,64}{r}$ In the catalytic process, the initial step of binding the $\mathrm{CO}_{2}$ molecule seems to be important because the sequence in the magnitude of the calculated $\mathrm{CO}_{2}$ adsorption energies $(\mathrm{Cu}<<\mathrm{TiC}<\mathrm{MoC})$ matches well the sequence found for the catalytic activity strongly suggesting that the $\mathrm{CO}_{2}$ adsorption energy can be taken as a descriptor of the 
catalytic activity.

\section{3. $\mathrm{H}_{2}$ Dissociation on TMC Supported Metal Clusters}

A series of previous studies have shown that the deposition of small coveragesof Au on $\mathrm{TiC}(001)$ enhances its catalytic activity for a variety of reactions, including hydrodesulfurization of thiophene, $\frac{30,80}{4}$ but also $\mathrm{SO}_{2}$ dissociation, ${ }^{81}$ with an activity higher than that of conventional $\mathrm{Ni} / \mathrm{MoS}_{\mathrm{x}}$ catalysts. This improved catalytic performance has been attributed to the polarization of

the $\mathrm{Au}$ cluster electron density triggered by the underlying TMC substrate. $\frac{33}{v}$ One may argue whether such synergic effect is specific of the $\mathrm{Au} / \mathrm{TiC}(001)$ system, or extendable to other metal clusters as well to other carbide substrates. In order to tackle this problem, a systematic study was undertaken in a couple of related studies concerning $\mathrm{H}_{2}$ dissociation. In these studies different combinations where explored such as maintaining a $\mathrm{Au}_{4}$ cluster on different carbide substrates, and testing also different late transition metal clusters, mainly $\mathrm{M}_{4}$, on $\mathrm{TiC}(001)$.

On the $\mathrm{TiC}(001)$ surface, $\mathrm{Au}_{4}$ clusters were found to be more stable than disperse $\mathrm{Au}$ adatoms and to preferentially adopt a square planar structure in which each of the Au adatoms sits on top of a surface $\mathrm{C}$ atom. $\frac{33}{\sqrt{2}}$ This type of structure was sampled for $\mathrm{Ag}, \mathrm{Cu}, \mathrm{Pd}$, and $\mathrm{Pt}$ on TiC(001) at the PW91 level; energetic and structural data is listed in Table $3{ }^{82}$ Adhesion energy strength of the cluster is relatively small for coinage $\mathrm{Ag}$ and $\mathrm{Au}$ metals, slightly stronger for $\mathrm{Cu}$, and clearly high for Pd and Pt. Regardless of the metal, the cluster receives a small amount of electron density from the TiC substrate, ranging $\sim 0.1-0.3$ e as predicted by Bader analysis. In spite of the small amount of charge transfer, the final value seems to be correlated with the adsorption strength since the clusters with larger adhesion energy are also those where the charge transfer is the larger. Finally, it is worth pointing out that the metal-metal distances of coinage $(\mathrm{Cu}, \mathrm{Au}, \mathrm{Ag})$ supported clusters are larger than those of the bulk $\frac{49}{\wedge}$ by more than $0.15 \AA$ whereas $\mathrm{Pd}$ and $\mathrm{Pt}$ supported clusters exhibit slight elongations/contractions of $0.05 \AA$ only. More important is that electron density seems to be specially polarized on the coinage metal clusters with clear differences with respect to supported Pd and Pt clusters as illustrated by the ELF plots reported in Figure 5. Thus, even somehow counterintuitive, the stronger adhesion of $\mathrm{Pt}$ and $\mathrm{Pd}$ is not translated into a higher electron density polarization, even considering the larger carbide $\rightarrow$ cluster charge transfer. Hence, based on ELF plots one would expect a higher catalytic activity on $\mathrm{Cu}_{4}, \mathrm{Ag}_{4}$, and $\mathrm{Au}_{4}$ clusters. 
Let us now discuss the interaction of molecular hydrogen with the carbide supported clusters. Both, $\mathrm{Pd}_{4} / \mathrm{TiC}$ and $\mathrm{Pt}_{4} / \mathrm{TiC}$ clusters interact strongly with $\mathrm{H}_{2}$ leading to adsorption energy values of -0.70 and $-0.87 \mathrm{eV}$, respectively (Table 4 ). These are slightly larger than the one corresponding to $\mathrm{H}_{2}$ adsorption on the clean $\mathrm{TiC}(001)$ surface pointing towards a preferential capture of $\mathrm{H}_{2}$ on the supported metal clusters which can act as trapping centers. The exothermicity of the dissociation reaction also changes when considering the process on the supported clusters but now in the opposite directions. For the clean $\operatorname{TiC}(001)$ surface, the reaction is clearly exothermic by $-0.43 \mathrm{eV}$ but in the case of $\mathrm{Pd}_{4} / \mathrm{TiC}$ and $\mathrm{Pt}_{4} / \mathrm{TiC}$, the process is quasi thermoneutral. For $\mathrm{Pt}_{4} / \mathrm{TiC}$, the reaction is slightly exothermic $\left(E_{\text {react }}=-0.16 \mathrm{eV}\right)$ but the activation energy is rather high $(>1 \mathrm{eV})$ implying an unfavorable kinetics. Thus $\mathrm{H}_{2}$ scission on this system would take place in the patches of clean $\mathrm{TiC}(001)$ rather than on the Pt supported particles. On $\mathrm{Pd}_{4} / \mathrm{TiC}$, the activation energy $(0.53 \mathrm{eV})$ is essentially equal to that on $\mathrm{TiC}(001)$ but here the reaction is slightly endothermic $\left(E_{\text {react }}=+0.12 \mathrm{eV}\right)$. Thus, again $\mathrm{H}_{2}$ scission would be more likely on the $\mathrm{TiC}(001)$ support, but now for thermodynamic reasons. In any case neither $\mathrm{Pd}_{4} / \mathrm{TiC}$ nor $\mathrm{Pt}_{4} / \mathrm{TiC}$ seem good systems for $\mathrm{H}_{2}$ dissociation, in line with the negligible electron polarization induced by the carbide substrate. This is quite surprising since $\mathrm{H}_{2}$ dissociation on $\mathrm{Pd}$ and $\mathrm{Pt}$ surfaces is favored with activation energies of $\sim 0-0.4 \mathrm{eV}$ at most $\frac{82}{4} \mathrm{~A}$ quite different situation is found when considering the $\mathrm{Cu}_{4} / \mathrm{TiC}, \mathrm{Ag}_{4} / \mathrm{TiC}$ and $\mathrm{Au}_{4} / \mathrm{TiC}$ systems. Here adsorption energies are rather small, and actually, one would expect them to be determined by vdW forces although these terms were not included in the series of papers commented here. However, $\mathrm{H}_{2}$ dissociation becomes sensibly exothermic; $-0.63 \mathrm{eV}$ for $\mathrm{Ag}_{4} / \mathrm{TiC}$, and more than $-1 \mathrm{eV}$ for both $\mathrm{Cu}_{4} / \mathrm{TiC}$ and $\mathrm{Au}_{4} / \mathrm{TiC}$, systems. Furthermore, the increase in exothermicity is, in some cases, accompanied by a reduction of the activation barrier. In the case of $\mathrm{Ag}_{4} / \mathrm{TiC}$, the calculated activation energy barrir is still sensibly high $(0.80 \mathrm{eV})$ but already markedly smaller than the corresponding values for the $\operatorname{Ag}(001)$ and $\operatorname{Ag}(111)$ surface which, for a comparable computational method, are of the order of $\sim 0.75-1.6 \mathrm{eV}$. In the case of $\mathrm{Cu}_{4} / \mathrm{TiC}$, the barrier is rather small $(0.34 \mathrm{eV})$, which implies a considerable reduction with respect to the $\sim 0.5-0.9 \mathrm{eV}$ activation energy barriers corresponding to the $\mathrm{Cu}(001)$ and $\mathrm{Cu}(111)$ extended surfaces. More surprisingly $\mathrm{H}_{2}$ dissociation becomes an almost barrierless process for $\mathrm{Au}_{4} / \mathrm{TiC}$ with an activation energy of $0.08 \mathrm{eV}$ only whereas significantly larger energy barriers of $0.75 \mathrm{eV}$ are | predicted for $\mathrm{H}_{2}$ dissociation on $\mathrm{Au}(111)$ and $\mathrm{Au}(001)$ extended surfaces $\frac{82}{\mathrm{r}}$ Calculations for a 
larger but still planar $\mathrm{Au}_{9}$ cluster supported on $\mathrm{TiC}(001)$ revealed a very similar situation, with an energy barrier of $0.20 \mathrm{eV}$ only, ${ }^{68}$ indicating that this type of effect is general enough for twodimensional supported small clusters.

The markedly reduced energy barrier on $\mathrm{Cu}_{4} / \mathrm{TiC}$ and $\mathrm{Au}_{4} / \mathrm{TiC}$, suggests that $\mathrm{H}_{2}$ dissociation will likely take place in the supported metal cluster centers, due to the improved kinetics and thermodynamic and in spite of the small interaction with $\mathrm{H}_{2}$. In the case of $\mathrm{Cu}_{4} / \mathrm{TiC}$, the $\mathrm{H}$ adatoms arising from dissociation remain bridging opposite $\mathrm{Cu}-\mathrm{Cu}$ bonds whereas on $\mathrm{Au}_{4} / \mathrm{TiC}$ one $\mathrm{H}$ remains on top of a $\mathrm{Au}$ atom and the other is spilled over the carbide surface, attaching to a neighboring surface $\mathrm{C}$ atom. Nevertheless, such spilling is only $0.28 \mathrm{eV}$ lower in energy with respect to the situation where both $\mathrm{H}$ atoms remain on-top of $\mathrm{Au}$ atoms $\frac{68}{\mathrm{v}} \mathrm{Thus}$, the carbide substrate can act as an $\mathrm{H}$ adatom reservoir. All in all both $\mathrm{Cu}_{4} / \mathrm{TiC}$ and $\mathrm{Au}_{4} / \mathrm{TiC}$ systems are predicted to be excellent catalysts for $\mathrm{H}_{2}$ dissociation and hence, likely to be especially active in hydrogenation reactions.

In a subsequent study the effect of different carbide substrates, $\mathrm{ZrC}, \mathrm{VC}$, and $\delta$-MoC(001) surfaces was analyzed by studying $\mathrm{H}_{2}$ dissociation on the supported $\mathrm{Au}_{4}$ cluster which, according to the previous discussion, is surely, the most promising candidate. $\frac{70}{4}$ Results on Table 4 reveal that $\mathrm{H}_{2}$ adsorption energy is not enhanced by any of these carbide substrates except in the case of $\mathrm{ZrC}$ which displays an adsorption energy $(-0.24 \mathrm{eV})$ somehow larger than for $\mathrm{Au}_{4} / \mathrm{TiC}$. However, for $\mathrm{H}_{2}$ dissociation, the exothermicity becomes reduced by at least $0.4 \mathrm{eV}$ compared to $\mathrm{Au}_{4} / \mathrm{TiC}$ and the activations energy increased to $\sim 0.25-0.35 \mathrm{eV}$. In any case, a comparison with $\mathrm{H}_{2}$ dissociation on pristine surfaces as reported in Table 1 reveals that the reaction is kinetically and thermodynamically favorable for $\mathrm{Au}_{4} / \mathrm{ZrC}(001)$ and $\mathrm{Au}_{4} / \mathrm{VC}(001)$, with a remarkable increase on the reaction exothermicity with respect to the clean TMC surface. On the contrary, the effect of $\delta-\mathrm{MoC}$ on the $\mathrm{Au}_{4}$ cluster is not that spectacular, since the exothermicity of the reaction remains unaltered even if the activation energy of $0.34 \mathrm{eV}$ is still rather small.

Concerning the reaction mechanism, both $\mathrm{Au}_{4} / \mathrm{TiC}$ and $\mathrm{Au}_{4} / \mathrm{ZrC}$ systems exhibit the same trend with identical atomic displacements, i.e. $\mathrm{H}$ spillover to the TMC surface. However, in the case of the $\mathrm{Au}_{4} / \mathrm{VC}$ and $\mathrm{Au}_{4} / \delta$-MoC systems, $\mathrm{H}_{2}$ adsorbs on top of a cluster metal atom, eventually dissociating and placing each of the formed $\mathrm{H}$ atoms on top of vicinal cluster metal atoms. In these cases, the lack of spillover to the carbide is in accord with the surface instability 
of $\mathrm{C}-\mathrm{H}$ bond formation as shown in Figure 2.

To summarize, $\mathrm{Au}$ and $\mathrm{Cu}$ clusters are apparently the best metal active centers for the dissociation of $\mathrm{H}_{2}$ when supported on $\mathrm{TiC}(001)$. This is due to the quite reduced energy barriers and to the stabilization of the dissociated $\mathrm{H}$ atoms. Using other carbides as supports results in larger $\mathrm{H}_{2}$ dissociation energy barriers and reduced exothermicity, but not to the point of making them prohibitive at room temperature. In the case of using $\mathrm{TiC}$ or $\mathrm{ZrC}$ as supports one has the additional beneficial effect of $\mathrm{H}$ adatom spillover to the carbide surface which, on the one hand, regenerates the metal active sites for further hydrogen dissociation and, on the other hand, provide an efficient $\mathrm{H}$ reservoir for subsequent hydrogenation reactions. On the contrary, use of $\mathrm{VC}$ and $\delta$-MoC as supports of $\mathrm{Au}$ and $\mathrm{Cu}$ small nanoparticles difficult $\mathrm{H}$ spillover, due to the surface instability of $\mathrm{C}-\mathrm{H}$ groups. Thus, the metal cluster used and the carbide substrate employed are two factors to fine tune the catalytic activity of these new type of systems at will.

\section{4. $\mathrm{CO}_{2}$ Dissociation on TMC-Supported Metal Clusters}

In the previous section it has been shown that small $\mathrm{Cu}$ and $\mathrm{Au}$ clusters supported on a $\mathrm{TiC}(001)$ surface are ideal model catalysts for $\mathrm{H}_{2}$ adsorption and dissociation, featuring small energy barriers which would allow the process to occur even at room temperature. Moreover, the above mentioned spillover process of $\mathrm{H}$ adatoms to the underlying $\mathrm{TiC}(001)$ surface provides an efficient $\mathrm{H}$ reservoir. At this point, the question is whether the enhanced catalytic activity of $\mathrm{Au}_{4} / \mathrm{TiC}(001)$ and $\mathrm{Cu}_{4} / \mathrm{TiC}(001)$ systems for $\mathrm{H}_{2}$ dissociation can be used in hydrogenation reactions. The case of $\mathrm{CO}_{2}$ hydrogenation to methanol is particularly interesting because of the potential use of a global warming gas directly as feedstock for a fuel (methanol) synthesis.

In a first study, $\mathrm{CO}_{2}$ adsorption on $\mathrm{Cu} / \mathrm{TiC}$ and $\mathrm{Au} / \mathrm{TiC}$ was investigated using the PW91 density functional and the $\mathrm{Au}_{4} / \mathrm{TiC}(001)$ and $\mathrm{Cu}_{4} / \mathrm{TiC}(001)$ model systems. This initial study revealed that $\mathrm{CO}_{2}$ becomes activated adopting a bent molecule as discussed in a previous section for $\mathrm{MoC}$ and $\mathrm{Mo}_{2} \mathrm{C}$. However, here the interaction is quite strong. In the case of $\mathrm{Cu}_{4} / \mathrm{TiC}$ the adsorption energy becomes $-1.12 \mathrm{eV}$ with the molecule lying almost planar to the $\mathrm{Cu}_{4}$ supported cluster but with an O-C-C angle of $117^{\circ}$ (Figure 6) $\frac{22}{4}$ A similar situation is found for the case of $\mathrm{Au}_{4} / \mathrm{TiC}$, the O-C-O angle is larger $\left(128^{\circ}\right)$ and the adsorbed molecule bridges a $\mathrm{Au}-\mathrm{Au}$ bond through a $\mathrm{C}-\mathrm{O}$ bond with the other $\mathrm{C}-\mathrm{O}$ bond pointing towards the vacuum. The adsorption energy of this conformation, $-0.62 \mathrm{eV}$, is smaller than in the $\mathrm{Cu} / \mathrm{TiC}$ case, and of the same 
magnitude to $\mathrm{TiC}(001)$. However, the important point here is that, in both cases, the $\mathrm{CO}_{2}$ molecule becomes activated. This is not only observed in the molecular bending consistent with a charged $\mathrm{CO}_{2}{ }^{{ }^{-}}$adsorbed species but is also consistent with the elongation of the $\mathrm{C}-\mathrm{O}$ bond lengths reaching values of 1.22 and $1.31 \AA$ in $\mathrm{Au}_{4} / \mathrm{TiC}$ and even larger (1.29 and $\left.1.36 \AA\right)$ in the case of $\mathrm{Cu}_{4} / \mathrm{TiC}$ which is well in agreement with the trend in adsorption. In principle, adsorption energy and catalytic activity follow the same trend and this is precisely the case here as observed in Figure 7. $\mathrm{A} \mathrm{Cu} / \mathrm{TiC}$ model catalyst is found to be 5-12 times more active than $\mathrm{Cu} / \mathrm{ZnO}$ catalyst, and even $\mathrm{Au} / \mathrm{TiC}$ surpasses the commercial catalyst. Moreover, the catalytic activity is 170-500 times much larger than on $\mathrm{Cu}(111)$, with an apparent activation energy decrease from $1.1 \mathrm{eV}$ on $\mathrm{Cu}(111)$ to $0.5 \mathrm{eV}$ on $\mathrm{Cu} / \mathrm{TiC}(001) . \frac{21}{\mathrm{v}}$

The results just described evidence the potential of $\mathrm{TiC}$ in methanol synthesis as a support for $\mathrm{Cu}$ clusters. However, one must realize that the beneficial effect of the support on the metal cluster through electron polarization may be lost for larger clusters. This is confirmed by experiments relying on Scanning Tunneling Microscopy (STM) distribution heights which show that highest catalytic activities correspond to small doses of $\mathrm{Cu}, \sim 0.1 \mathrm{ML}$. In this situation, a majority of clusters have one atomic layer height. $\frac{22}{v}$ The calculated adsorption energy $\mathrm{CO}_{2}$ on $\mathrm{Cu} / \mathrm{TiC}$ and $\mathrm{Au} / \mathrm{TiC}$ decrease for slightly larger clusters but keeping planarity with values of 0.59 and $-0.37 \mathrm{eV}$ for $\mathrm{Cu}_{9}$ and $\mathrm{Au}_{9}$ supported clusters. For larger, three-dimensional $\mathrm{M}_{13}$ or $\mathrm{M}_{29}$ supported particles, the calculated adsorption energy of $\mathrm{CO}_{2}$ becomes negligible. $\frac{21}{{ }_{r}}$

In addition to methanol, $\mathrm{CO}_{2}$ hydrogenation on $\mathrm{Cu} / \mathrm{TiC}$ and $\mathrm{Au} / \mathrm{TiC}$ model catalysts systems leads to $\mathrm{CO}$ even in larger amounts than methanol. In order to investigate the origin of $\mathrm{CO}$, the dissociation of $\mathrm{CO}_{2}$ into $\mathrm{CO}$ and $\mathrm{O}$ was further investigated on both $\mathrm{Cu} / \mathrm{TiC}$ and $\mathrm{Au} / \mathrm{TiC}$ model catalyst by means of pertinent DF calculations and for the case of $\mathrm{Cu}_{4} / \mathrm{TiC}(001)$ model, the reaction profile is shown in Figure $8 .^{21}$ The direct $\mathrm{C}-\mathrm{O}$ bond scission is found to be an endothermic process by $0.22 \mathrm{eV}$, with an activation barrier of $0.81 \mathrm{eV}$. However, the energy released by the adsorption of $\mathrm{CO}_{2}(-1.12 \mathrm{eV})$ could be used to overcome the dissociation barrier. However, an alternative route exists for $\mathrm{CO}$ formation through the reverse water-gas shift reaction. Considering that $\mathrm{TiC}(001)$ is a $\mathrm{H}$ adatom reservoir, a $\mathrm{HOCO}$ intermediate can be formed, which eventually would decompose into $\mathrm{OH}$ and $\mathrm{CO}$. Figure 8 shows that the formation of $\mathrm{HOCO}$ on $\mathrm{Cu}_{4} / \mathrm{TiC}(001)$ is an endothermic process similar to $\mathrm{CO}_{2}$ splitting, but with a smaller 
activation energy of $0.57 \mathrm{eV}$. However, $\mathrm{HOCO}$ decomposition is an exothermic process with quite small energy barrier of $0.18 \mathrm{eV}$. Thus, this route seems to be the most favorable for $\mathrm{CO}$ production. Note that despite isomerization of $\mathrm{HOCO}$ into $\mathrm{HCOO}$ is an exothermic process by $1.03 \mathrm{eV}$, the activation energy associated is sensibly larger, $0.59 \mathrm{eV}$, and therefore, unlikely. The same reaction mechanism is found to be the preferred for $\mathrm{CO}_{2}$ hydrogenation on $\mathrm{Au}_{4} / \mathrm{TiC}(001)$ system; the $\mathrm{HOCO}$ formation step is endothermic by $0.37 \mathrm{eV}$ with an activation energy of 0.70 $\mathrm{eV}$. This cost can be, in part, compensated by the $\mathrm{CO}_{2}$ adsorption energy of $-0.62 \mathrm{eV}$. Once $\mathrm{HOCO}$ is formed, it is likely to dissociate almost spontaneously into $\mathrm{CO}$ and $\mathrm{OH}$ as expected from the slight exothermicity $(-0.11 \mathrm{eV})$ and, especially, from the quite small energy barrier of $0.06 \mathrm{eV}$. As already found on $\mathrm{Cu}_{4} / \mathrm{TiC}(001), \mathrm{HCOO}$ formation, despite being a significantly exothermic step $(-0.64 \mathrm{eV})$, involves a larger barrier of $0.35 \mathrm{eV}$.

In summary, the methanol synthesis rate on $\mathrm{Cu}_{4}$ and $\mathrm{Au}_{4}$ clusters supported on $\mathrm{TiC}(001)$ surface is correlated with the easy $\mathrm{H}_{2}$ dissociation on the supported metal clusters and spillover to the carbide support, which acts as a $\mathrm{H}$ reservoir, but also with the strong adsorption of $\mathrm{CO}_{2}$ on the supported cluster which activates the molecule and favors $\mathrm{CO}$ formation through reverse water-gas shift reaction and $\mathrm{HOCO}$ intermediate formation. Despite $\mathrm{H}_{2}$ splitting is easier on $\mathrm{Au}_{4} / \mathrm{TiC}(001)-0.08 \mathrm{eV}$ compared to $0.37 \mathrm{eV}$ on $\mathrm{Cu}_{4} / \mathrm{TiC}(001)-\mathrm{HOCO}$ formation seems to be the determining step, which is easier on $\mathrm{Cu}_{4} / \mathrm{TiC}(001)-0.57 \mathrm{eV}$ compared to $0.70 \mathrm{eV}$ for $\mathrm{Au}_{4} / \mathrm{TiC}(001)$ - and these findings are in perfect agreement with experiments carried out on $\mathrm{Au} / \mathrm{TiC}$ and $\mathrm{Cu} / \mathrm{TiC}$ model catalysts.

\section{Conclusions}

Transition Metal Carbides (TMCs) are highly active catalyst for methanol synthesis by direct $\mathrm{CO}_{2}$ hydrogenation $\left(\mathrm{CO}_{2}+\mathrm{H}_{2} \rightarrow \mathrm{CH}_{3} \mathrm{OH}+\mathrm{H}_{2} \mathrm{O}\right)$ either per se, or as active supports for small late transition metal clusters, especially of $\mathrm{Cu}$ and $\mathrm{Au}$. Density Functional $(D F)$ calculations were used to study the interaction of $\mathrm{H}_{2}$ and of $\mathrm{CO}_{2}$ with (001) surfaces of many TMCs and subsequent decomposition reactions. The effect of having small later transition metal clusters on such process has been examined in depth and theoretical predictions confirmed by catalytic experiments on methanol and carbon monoxide formation.

For most of the carbide surfaces studied, $\mathrm{H}_{2}$ adsorption and dissociation is an exothermic process. $\mathrm{VC}$ and $\delta$ - $\mathrm{MoC}(001)$ constitute exceptions where dissociated $\mathrm{H}$ atoms form $\mathrm{C}-\mathrm{H}$ bond 
which highly distort the surface. Therefore, TMCs other than VC and $\delta$-MoC are ideal for hydrogenation reactions whereas $\mathrm{VC}$ and $\delta$-MoC can be used if hydrogenation wants to be prevented. $\mathrm{H}_{2}$ adsorption and dissociation on $\mathrm{TiC}$ and $\mathrm{ZrC}(001)$ surfaces is exothermic, although with significant energy barriers. Apparently, for $\mathrm{H}_{2}$ dissociation the $\mathrm{C}$ :Mo ratio seems to be a determinant factor, since $\beta-\mathrm{Mo}_{2} \mathrm{C}(001)$ surfaces display a high exothermicity, and presumably, low $\mathrm{H}_{2}$ dissociation energy barriers.

Test calculations including van der Waals forces reveal that dispersion does not play a role in the dissociation process of $\mathrm{H}_{2}$, or in $\mathrm{CO}_{2}$ adsorption and dissociation. Interestingly, $\mathrm{CO}_{2}$ becomes systematically activated when adsorbed in any of studied TMCs (001) surfaces. This is clear from the bent molecular structure of adsorbed $\mathrm{CO}_{2}$, carbide $\rightarrow \mathrm{CO}_{2}$ charge transfer, $\mathrm{C}-\mathrm{O}$ bond elongations, and $\mathrm{C}-\mathrm{C}$ bond formation with surface $\mathrm{C}$ atoms whenever they are exposed. The $\mathrm{CO}_{2}$ adsorption energy seems to be a good descriptor for methanol synthesis, since it follows the trend $\mathrm{Mo}_{2} \mathrm{C}>\mathrm{MoC}>\mathrm{TiC}>>\mathrm{Cu}$. In particular, Mo-terminated $\beta-\mathrm{Mo}_{2} \mathrm{C}(001)$ surface seem to be a rather good surface for $\mathrm{CO}_{2}$ dissociation, with a reasonable energy barrier of $0.76 \mathrm{eV}$ for a clear exothermic process of almost $-2 \mathrm{eV}$.

Using TMCs as supports for transition metals leads to a new family of catalyst with high potential in methanol synthesis from $\mathrm{CO}_{2}$. Two-dimensional late transition metal $(\mathrm{Cu}, \mathrm{Ag}$, and $\mathrm{Au})$ clusters in contact with $\mathrm{TMC}(001)$ surfaces undergo a charge polarization that enhances their reactivity. In particular $\mathrm{Cu}_{4}$ and $\mathrm{Au}_{4}$ clusters on $\mathrm{TiC}(001)$ surface are ideal combinations, in which $\mathrm{H}_{2}$ dissociation is powered at metal clusters, increasing the process exothermicity beyond $-1 \mathrm{eV}$, and decreasing the energy barriers below $0.4 \mathrm{eV}$. Moreover, $\mathrm{H}$ adatom spillover on the $\mathrm{TiC}(001)$ surface is possible, leading to a convenient $\mathrm{H}$ reservoir. $\mathrm{Cu}_{4} / \mathrm{TiC}(001)$ and $\mathrm{Au}_{4} / \mathrm{TiC}(001)$ systems reveal a stronger adsorption of $\mathrm{CO}_{2}$ with the adsorption energy correlating with methanol formation rate on model systems: $\mathrm{Cu} / \mathrm{TiC}(001)>\mathrm{Au} / \mathrm{TiC}(001)>\mathrm{Cu} / \mathrm{ZnO}(001)>>$ $\mathrm{Cu}(111)$ thus posing small disperse $\mathrm{Cu}$ and even $\mathrm{Au}$ clusters supported on $\mathrm{TiC}$ as excellent catalyst for methanol synthesis, dozens of times better than commercial $\mathrm{Cu} / \mathrm{ZnO}$ based catalysts. The mechanistic study reveals that $\mathrm{C}-\mathrm{O}$ bond cleavage is best carried by $\mathrm{HOCO}$ formation and subsequent decomposition, with energy barriers of 0.7 and $0.57 \mathrm{eV}$ for carbide-supported $\mathrm{Au}_{4}$ and $\mathrm{Cu}_{4}$ clusters, respectively.

To summarize, metals supported on transition metal carbides constitute a new class of 
supported catalysts with interesting properties as illustrated by the facility to hydrogenate $\mathrm{CO}_{2}$ to methanol on the $\mathrm{Cu} / \mathrm{TiC}$ and $\mathrm{Au} / \mathrm{TiC}$ systems. Additional work is required to test other metal/carbide combinations and to explore their activity in a larger number of chemical reactions.

\section{Acknowledgements}

The research carried out at the Universitat de Barcelona was supported by the Spanish MINECO grant CTQ2012-30751 grant and, in part, by Generalitat de Catalunya (grants 2014SGR97 and XRQTC). The research carried out at BNL was supported by the U.S. Department of Energy, Chemical Sciences Division (DE-AC02-98CH10886). S.P.P acknowledges financial support from Spanish MEC predoctoral grant associated to CTQ-2012-30751; F.V. thanks the MINECO for a postdoctoral Ramón y Cajal grant (RYC-2012-10129); F.I. acknowledges additional support through the ICREA Academia award for excellence in research. Computational time at the MARENOSTRUM supercomputer has been provided by the Barcelona Supercomputing Centre through a grant from Red Española de Supercomputación. 
Table 1. Adsorption energy of molecularly $\left(\boldsymbol{E}_{\boldsymbol{H}_{2}}^{a d s}\right)$ and dissociatively $\left(\boldsymbol{E}_{2 \boldsymbol{H}}^{a d s}\right)$ adsorbed hydrogen, activation $\left(\boldsymbol{E}_{\text {act }}\right)$ and reaction $\left(\boldsymbol{E}_{\text {react }}\right)$ energies for the dissociation of molecular hydrogen on the clean TMC(001) surfaces as predicted by different exchange-correlation (xc) functionals. All values are given in $\mathrm{eV}$.

\begin{tabular}{|c|c|c|c|c|c|}
\hline System & $\mathbf{x c}$ & $E_{H_{2}}^{a d s}$ & $E_{2 H}^{a d s}$ & $E_{a c t}$ & $\overline{E_{\text {react }}}$ \\
\hline \multirow[t]{2}{*}{ TiC(001) } & $\mathrm{PW91}^{a}$ & -0.48 & -0.91 & 0.52 & -0.43 \\
\hline & PW91 $^{b}$ & -0.05 & -0.35 & 0.60 & -0.30 \\
\hline $\operatorname{ZrC(001)}$ & $\mathrm{PW}^{c}{ }^{c}$ & -0.66 & -1.10 & 0.80 & -0.44 \\
\hline $\mathrm{VC}(001)$ & $\mathrm{PW}^{\circ}{ }^{c}$ & 0.04 & 0.28 & - & 0.24 \\
\hline \multirow[t]{3}{*}{$\delta$-МoC $(001)$} & $\mathrm{PW}^{c}{ }^{c}$ & 0.04 & -0.46 & - & -0.50 \\
\hline & PBE & -0.47 & -1.08 & - & -0.61 \\
\hline & PBE-vdW & -0.75 & -1.28 & - & -0.53 \\
\hline \multirow[t]{2}{*}{$\begin{array}{c}\beta-\mathrm{Mo}_{2} \mathrm{C}(001)- \\
\mathrm{C} \\
\end{array}$} & PBE & -0.02 & -2.54 & - & -2.52 \\
\hline & PBE-vdW & -0.40 & -2.78 & - & -2.38 \\
\hline \multirow[t]{2}{*}{$\begin{array}{c}\beta-\mathrm{Mo}_{2} \mathrm{C}(001)- \\
\mathrm{Mo}\end{array}$} & PBE & -0.76 & -1.96 & - & -1.20 \\
\hline & PBE-vdW & -0.89 & -2.10 & - & -1.21 \\
\hline
\end{tabular}

${ }^{a}$ Ref. $68,{ }^{b}$ Ref. $67,{ }^{c}$ Ref. 70 
Table 2. Adsorption energy of $\mathrm{CO}_{2}\left(\boldsymbol{E}_{\boldsymbol{C O}}^{a d s}\right)$ on several TMC(001) surfaces, O-C-O angle ( $\left.\alpha\right)$, C-O $\left(\boldsymbol{d}_{\boldsymbol{C o}}\right)$ and $\mathrm{C}-\mathrm{C}\left(\boldsymbol{d}_{\boldsymbol{C} C}\right)$ distance, and net charge on the admolecule. Values are given in $\mathrm{eV}$, degrees, $\AA$, and electrons, respectively.

\begin{tabular}{|c|c|c|c|c|c|c|}
\hline System & $\mathbf{x c}$ & $E_{C O_{2}}^{a d s}$ & & $d_{C O}$ & $d(C C)$ & $\Delta Q$ \\
\hline \multirow[t]{2}{*}{ TiC(001) } & $\mathrm{PW}^{a}{ }^{a}$ & -0.22 & - & - & - & - \\
\hline & $\mathrm{PW}^{b}{ }^{b}$ & -0.62 & - & 1.29 & 1.48 & - \\
\hline WC(001)-W & $\mathrm{PW}^{\mathrm{C}}{ }^{\mathrm{C}}$ & -0.99 & 121 & - & - & -1.56 \\
\hline \multirow[t]{4}{*}{$\delta$-MoC $(001)$} & $\mathrm{PBE}^{d}$ & -0.82 & 122 & 1.30 & 1.46 & -0.93 \\
\hline & PBE-vdW $^{d}$ & -1.33 & 121 & 1.30 & 1.46 & -1.02 \\
\hline & $\mathrm{PBE}^{d}$ & -0.74 & 129 & 1.29 & 1.47 & -0.76 \\
\hline & PBE-vdW $^{d}$ & -1.35 & 129 & 1.29 & 1.47 & -0.93 \\
\hline \multirow[t]{2}{*}{$\beta-\mathrm{Mo}_{2} \mathrm{C}(001)-\mathrm{C}$} & $\mathrm{PBE}^{d}$ & -0.61 & 122 & $1.21 / 1.42$ & 1.47 & -0.76 \\
\hline & PBE-vdW $^{d}$ & -1.02 & 122 & $1.21 / 1.42$ & 1.47 & -0.75 \\
\hline \multirow[t]{2}{*}{$\beta$-Мo 2 C(001)-Mo } & $\mathrm{PBE}^{d}$ & -1.38 & 133 & 1.27 & - & -1.26 \\
\hline & PBE-vdW $^{d}$ & -1.76 & 133 & 1.27 & - & -1.27 \\
\hline
\end{tabular}

${ }^{a}$ Ref. 67, ${ }^{b}$ Ref. $64,{ }^{c}$ Ref. $76,{ }^{d}$ Ref. 77 
Table 3. Adhesion energy per metal atom $\left(E_{a d h}\right)$ of $\mathrm{M}_{4}$ clusters $(\mathrm{M}=\mathrm{Au}, \mathrm{Ag}, \mathrm{Cu}, \mathrm{Pd}, \mathrm{Pt})$ on the $\mathrm{TiC}(001)$ surface, their metal-metal distance $\left(d_{M M}\right)$ and amount of charge transfer $(\Delta Q)$. Values are in $\mathrm{eV}, \AA$ and electrons. $\frac{82}{\mathrm{r}}$

\begin{tabular}{|c|c|c|c|}
\hline System & $\boldsymbol{E}_{\boldsymbol{a d h}}$ & $\boldsymbol{d}_{\boldsymbol{M M}}$ & $\boldsymbol{\Delta Q}$ \\
\hline $\mathbf{P t}_{\mathbf{4}}$ & -2.29 & 2.76 & -0.29 \\
\hline $\mathbf{P d}_{\mathbf{4}}$ & -1.93 & 2.83 & -0.16 \\
\hline $\mathbf{C u}_{\mathbf{4}}$ & -1.28 & 2.42 & -0.17 \\
\hline $\mathbf{A u}_{\mathbf{4}}$ & -0.86 & 2.78 & -0.10 \\
\hline $\mathbf{A g}_{\mathbf{4}}$ & -0.78 & 2.75 & -0.06 \\
\hline
\end{tabular}


Table 4. Adsorption energy of molecularly and dissociatively adsorbed hydrogen, activation and reaction energies for the dissociation of molecular hydrogen on the $\mathrm{TMC}(001)$ supported metal clusters. Symbols and units are as in Table 1.

\begin{tabular}{|c|c|c|c|c|}
\hline System & $E_{H_{2}}^{a d s}$ & $E_{2 H}^{a d s}$ & $E_{a c t}$ & $E_{\text {react }}$ \\
\hline $\mathrm{Pt}_{4} / \mathrm{TiC}(001)^{a}$ & -0.87 & -1.03 & 1.16 & -0.16 \\
\hline $\operatorname{Pd}_{4} / \mathrm{TiC}(001)^{a}$ & -0.70 & -0.58 & 0.53 & 0.12 \\
\hline $\mathrm{Cu}_{4} / \mathrm{TiC}(001)^{a}$ & 0.01 & -1.21 & 0.37 & -1.22 \\
\hline $\mathrm{Ag}_{4} / \mathrm{TiC}(001)^{a}$ & -0.01 & -0.64 & 0.80 & -0.63 \\
\hline $\mathrm{Au}_{4} / \mathrm{TiC}(001)^{b}$ & 0.01 & -1.10 & 0.08 & -1.11 \\
\hline $\mathrm{Au}_{4} / \mathrm{ZrC}(001)^{c}$ & -0.24 & -0.96 & 0.25 & -0.72 \\
\hline $\mathrm{Au}_{4} / \mathrm{VC}(001)^{c}$ & 0.01 & -0.64 & 0.36 & -0.65 \\
\hline $\mathrm{Au}_{4} / \delta-\mathrm{MoC}(001)^{c}$ & -0.03 & -0.54 & 0.34 & -0.51 \\
\hline
\end{tabular}

${ }^{a}$ Ref. 68, ${ }^{b}$ Ref. $67,{ }^{c}$ Ref. 70 
Figure 1: Schematic representation of the structure of molecular hydrogen adsorbed on $\mathrm{TiC}(001)$. Grey, blue, and white spheres denote $\mathrm{C}$, $\mathrm{Ti}$, and $\mathrm{H}$ atoms, respectively.

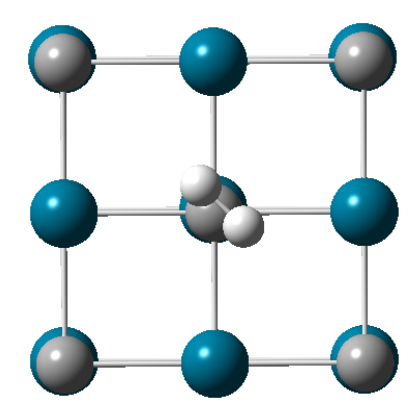


Figure 2: Structural deformation of $\mathrm{VC}$ and $\delta$-MoC induced by the presence of adsorbed atomic hydrogen. blue, brown, and white spheres denote $\mathrm{C}$, metal ( $\mathrm{V}$ or Mo), and $\mathrm{H}$ atoms, respectively.

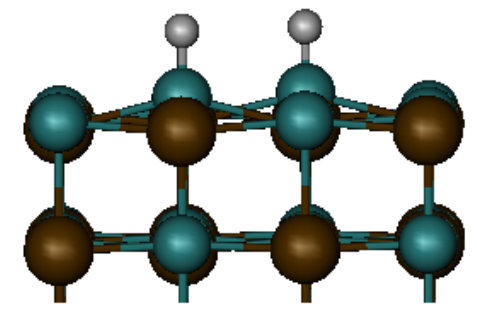

$\operatorname{VC}(001)$

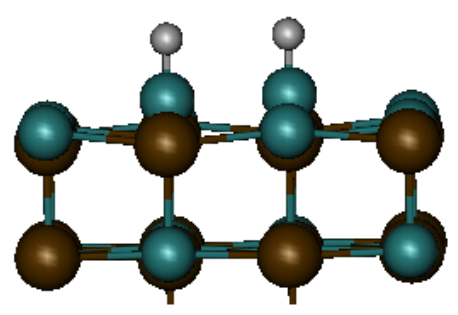

$\delta-\operatorname{MoC}(001)$ 
Figure 3: Calculated adsorption geometry for $\mathrm{CO}_{2}$ on $\mathrm{TiC}(001)$. Red, light grey, and blue spheres denote $\mathrm{O}, \mathrm{C}$, and $\mathrm{Ti}$ atoms, respectively.

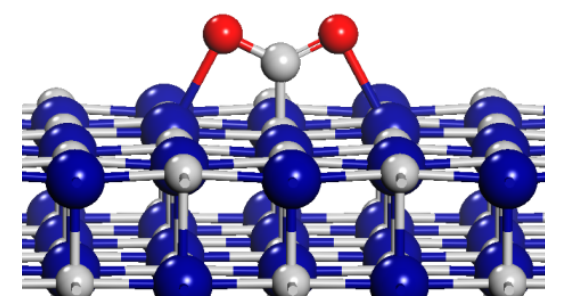


Figure 4: Variation of the total $\mathrm{O} 1 s$ signal after dosing $\mathrm{CO}_{2}$ to polycrystalline $\mathrm{MoC}$ and a $\beta$ $\mathrm{Mo}_{2} \mathrm{C}(001)-\mathrm{Mo}$ surface. In the case of $\beta-\mathrm{Mo}_{2} \mathrm{C}(001)-\mathrm{Mo}$, the adsorbed $\mathrm{CO}_{2}$ underwent dissociation into $\mathrm{O}$ and $\mathrm{CO}$.

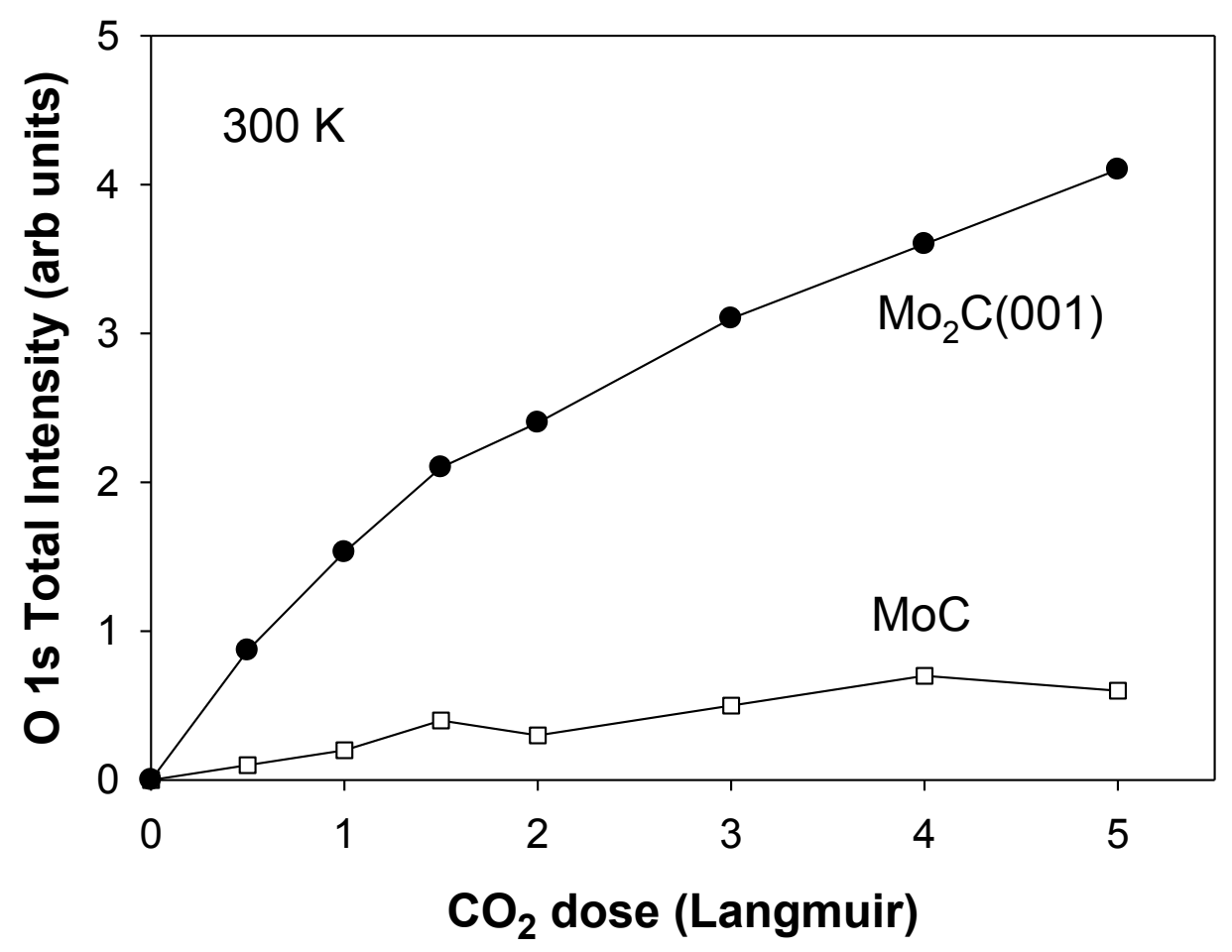


Figure 5: ELF plots for $\mathrm{H}_{2}$ on $\mathrm{M}_{4} / \mathrm{TiC}$ systems (M=Pt, $\left.\mathrm{Pd}, \mathrm{Cu}, \mathrm{Au}, \mathrm{Ag}\right)$

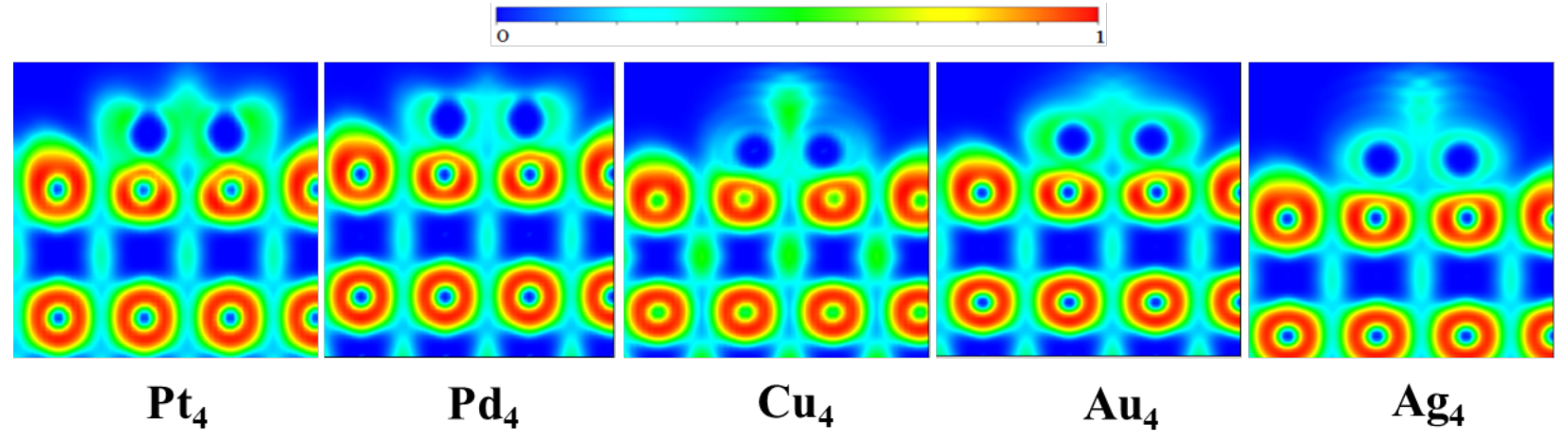


Figure 6: $\mathrm{CO}_{2}$ adsorbed on $\mathrm{Cu}_{4} / \mathrm{TiC}(001)$ (top) and $\mathrm{Au}_{4} / \mathrm{TiC}(001)$ (bottom). Left sketches are side views, whereas right sketches are top views.
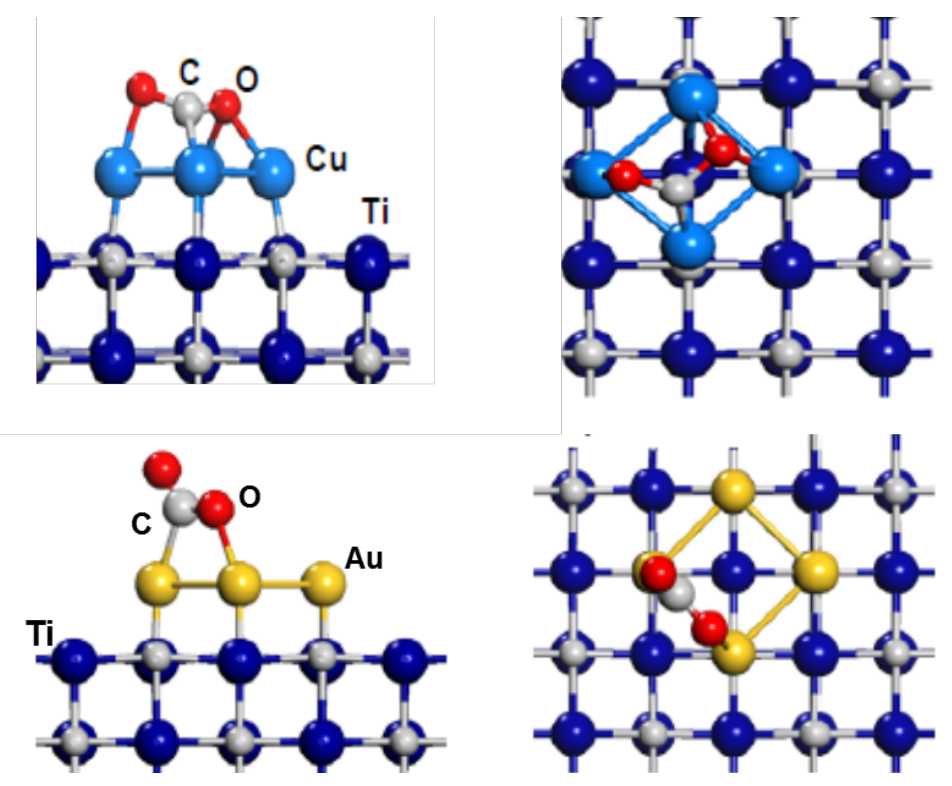
Figure 7. Arrhenius plot for methanol synthesis on $\mathrm{Cu}(111)$, a $\mathrm{ZnO}(001)$ surface pre-covered with $0.2 \mathrm{ML}$ of $\mathrm{Cu}$, clean $\mathrm{TiC}(001)$, and titanium carbide pre-covered with $0.1 \mathrm{ML}$ of $\mathrm{Au}$ or $\mathrm{Cu}$. In a batch reactor, the catalysts were exposed to $0.049 \mathrm{MPa}(0.5 \mathrm{~atm})$ of $\mathrm{CO}_{2}$ and $0.441 \mathrm{MPa}(4.5$ atm) of $\mathrm{H}_{2}$. The reported values are for steady state rates measured at temperatures of 600, 575, 550,525 and $500 \mathrm{~K}$.

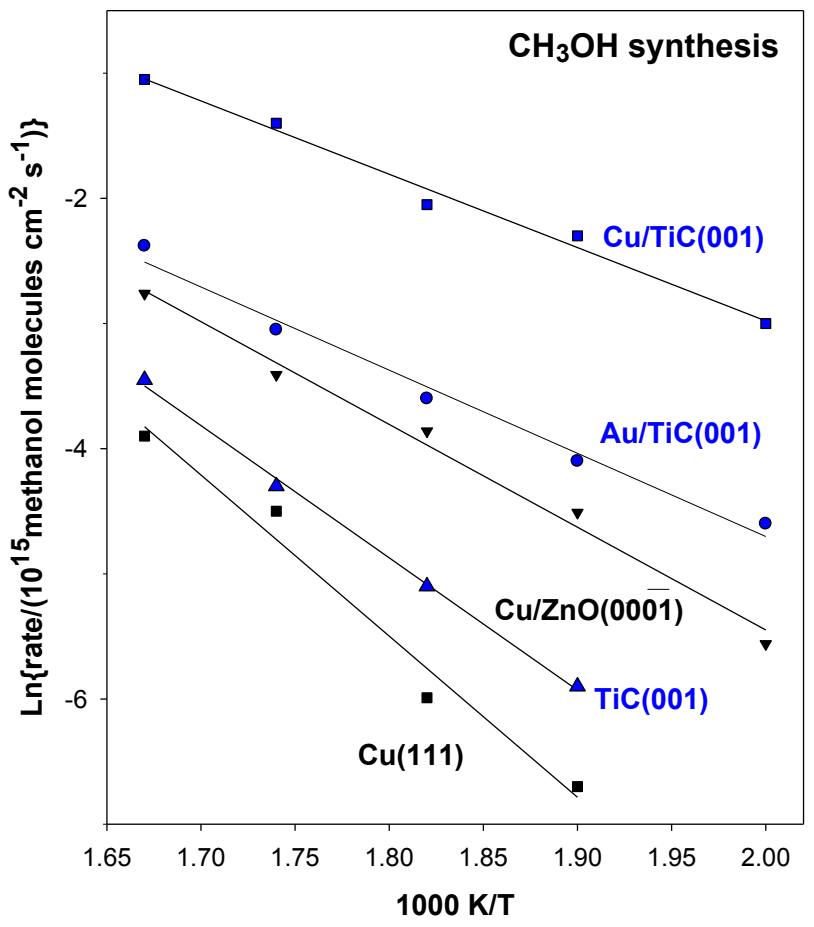


Figure 8. Reaction information for $\mathrm{CO}_{2}$ dissociation on $\mathrm{Cu}_{4} / \mathrm{TiC}(001)$ (top) and $\mathrm{HOCO}$ formation and decomposition (bottom). Color code as in Figure 6.

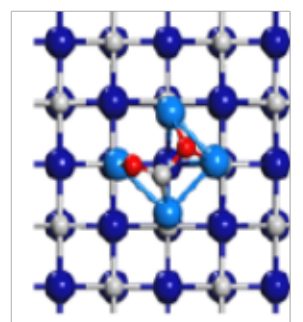

Reactant: $\mathrm{CO}_{2}$

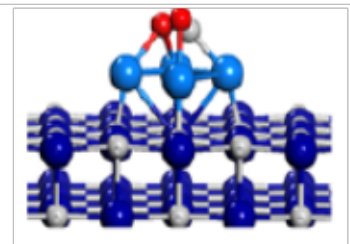

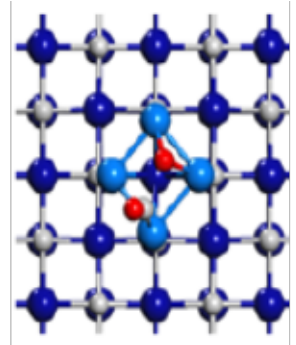

Transition state $\mathrm{E}_{\mathrm{a}}=\mathbf{0 . 8 1} \mathrm{eV}$

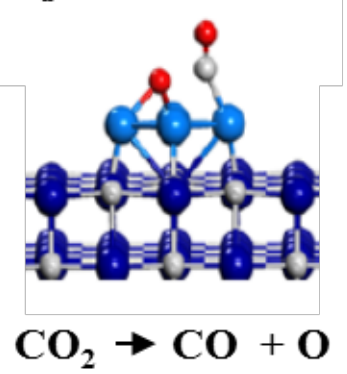

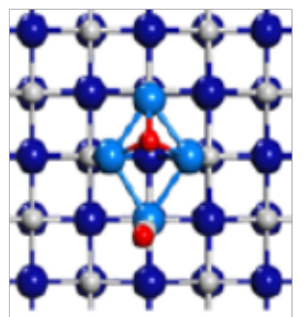

Products: $\mathrm{CO}+\mathrm{O}$ $\Delta \mathbf{E}=0.22 \mathrm{eV}$

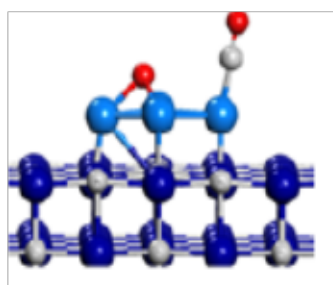

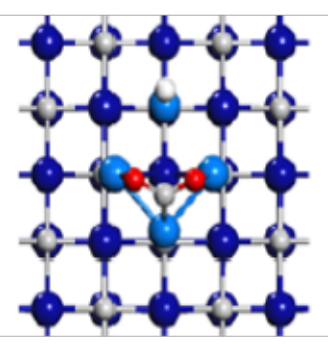
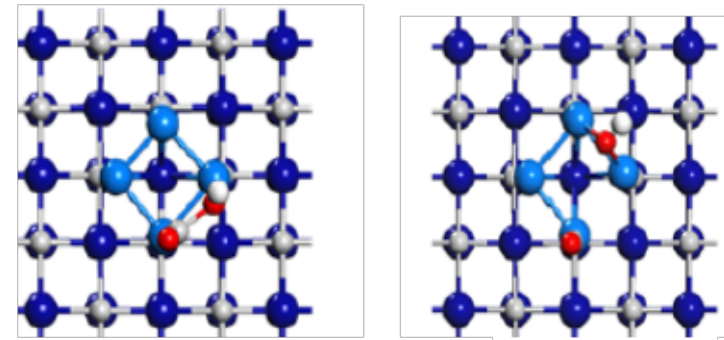

$$
\mathrm{CO}_{2}+\mathrm{H}
$$
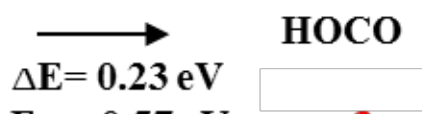

$\mathbf{E a}=0.57 \mathrm{eV}$
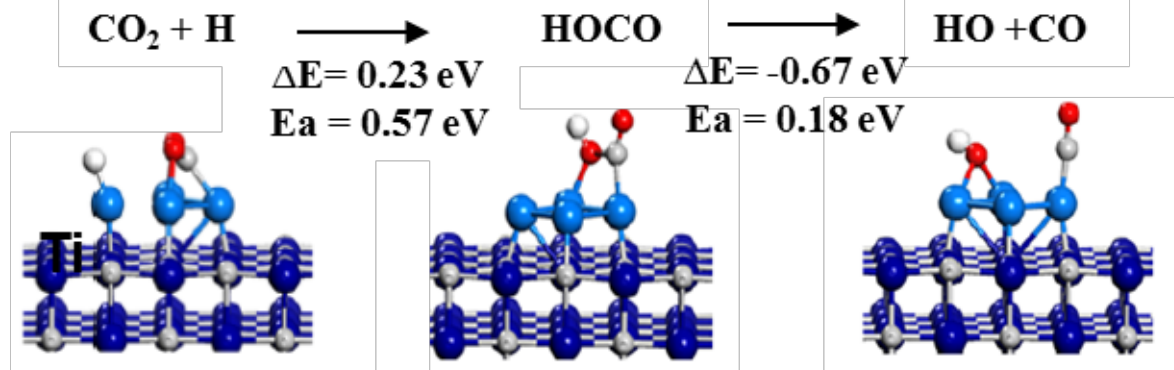


\section{References}

1. Karl TR, Trenberth KE (2003) Science 302:1719

2. U.E.I. Administration, International Energy Outlook 2013, Washington DC, 2013; http://www.eia.gov/forecasts/ieo/pdf/0484\%282013\%29.pdf.

3. Preti D, Resta C, Squarcialupi S, Fachinetti G (2011) Angew Chem Int Ed 50:12551

4. Behrens M, Studt F, Kasatkin I, Kühl S, Hävecker M, Abild-Pedersen F, Zander S, Girgsdies F, Kurr, P, Kniep BL, Tovar M, Fischer RW, Nørskov JK, Schlögl R (2012) Science 336:893.

5. Ansari M, Min BH, Mo YH, Park SE (2011) Green Chem 13:1416

6. Aresta M (2010) Carbon Dioxide as Chemical Feedstock, Wiley-VCH, New York

7 White SP, Allis RG, Moore J, Chidsey T, Morgan C, Gwynn W, Adams M (2005) Chem Geol 217: 387

8. Viñes F, Borodin A, Höfft O, Kempter V, Illas F (2005) Phys Chem Chem Phys 7:386

9. Habas MP, Mele F, Sodupe M, Illas F (1999) Surf Sci 431: 208

10. Lin J, Din Z, Hou Y, Wang X (2013) Scientific Rep 3:1056

11. Fernández-García M, Anderson JA (2003) Supported Metals in Catalysis, Catalytic Sciences Series, Vol. 5, Imperial College Press, London

12. French, SA, Sokol AA, Bromley ST, Catlow CRA, Rogers SC, King F, Sherwood P (2001) Angew Chem Int Ed 40:4437

13. Yoshihara J, Campbell CT (1996) J Catal 161:776

14. Yang Y, White MG, Liu P (2012) J Phys Chem C 116:248

15. Waugh KC (1992) Catal Today 15:51

16. Chichen GC, Denny PJ, Parker DG, Spencer MS, Whan DA (1987) Appl Catal 30:333

17. Lambert RM, Pacchioni G (2010) Chemisorption and Reactivity on Supported Clusters and Thin Films: Towards an Understanding of Microscopic Processes in Catalysis, NATO Science Series

18. Baumer M , Freund HJ (1999) Prog Surf Sci 61: 127

19. Stacchiola DJ, Senanayake SD, Liu L, Rodriguez JA (2013) Chem Rev 113:4373

20. Thomas JM, Thomas WJ (1996) Principles and Practice of Heterogeneous Catalysis, Wiley-VCH, New York 
21. Rodriguez JA, Evans J, Feria L, Vidal AB, Liu P, Nakamura K, Illas F (2013) J Catal 307:162

22. Vidal AB, Feria L, Evans J, Takahashi Y, Liu P, Nakamura K, Illas F, Rodriguez JA (2012) J Phys Chem Lett 3:2275

23 Posada-Pérez S, Viñes F, Ramirez PJ, Vidal AB, Rodriguez JA, Illas F (2014) Phys Chem Chem Phys in press

24. Kubas GJ (2009) J Organomet Chem 694:2648

25. Tøpsoe H, Clausen BS, Massoth FE (1996) Hydrotreating Catalysis: Science and Technology, Springer, Berlin

26. Bond GC (1998) Heterogeneous Catalysis: Principles and Applications, $2^{\text {nd }}$ ed., Oxford University Press: Oxford

27. Iyngaran P, Madden DC, Jenkins SJ, King DA (2011) Proc Natl Acad Sci 108:925

28. Claus P (1998) Top Catal 5:51

29. Ouchaib T, Massardier J, Renouprez A (1989) J Catal 119:51

30. Rodriguez JA, Liu P, Takahashi Y, Nakamura K, Viñes F, Illas F (2009) J Am Chem Soc 131:8595

31. Rodriguez JA, Liu P, Takahashi Y, Nakamura K, Viñes F, Illas F (2010) Top Catal 53:393

32 Corma A, Boronat M, González S, Illas F (2007) Chem Comm 3371

33. Rodriguez JA, Viñes F, Illas F, Liu P, Takahashi Y, Nakamura K (2007) J Chem Phys 127:211102

34. Toth LE (1971) Transition Metal Carbides and Nitrides, Academic Press, New York

35. Oyama ST (1992) Catal Today 15:179

36 Chorkendorff I, Niemantsverdriet JW (2007) Concepts of Modern Catalysis and Kinetics, 2nd ed.; Wiley-VCH Verlag GmbH \& Co KGaA: Weinheim, Germany.

37. Liu P, Rodriguez JA (2004) J Chem Phys 120:5414

38. Viñes F, Sousa C, Liu P, Rodriguez JA, Illas F (2005) J Chem Phys 122:174709

39. Kitchin JR, Nørskov JK, Barteau MA, Chen JG (2005) Catal Today 105:66

40. Rodriguez JA, Illas F (2012) Phys Chem Chem Phys 14: 427 
41. Rodriguez JA, Viñes F, Liu P, Illas F (2010) Model Systems in Catalysis: From Single Crystal and Size-Selected Clusters to Supported Enzyme Mimics, R. Rioux (Rd.), Springler Verlag, ISBN 978-0-387-98041-6. Springer-Verlag New York, p. 117

42 Rodriguez JA, Liu P, Nakamura K, Illas F (2013) Environmental Catalysis over goldbased materials, G. Avgouropoulos and T. Tabakova Editors, Royal Society of Chemistry, RSC Catalysis Series No. 13, ISBN: 978-1-84973-571-1

43. Kresse G., Furthmuüller J (1996) Phys Rev B: Condens Matter Mater Phys 54:11169

44. Delley B (1990) J Chem Phys 92:508

45. Perdew JP, Burke K, Ernzerhof M (1996) Phys Rev Lett 77:3865

46. Hammer B, Hansen LB, Nørskov JK (1999) 59:7413

47. Perdew JP, Wang Y (1992) Phys Rev B 45:13244

48. Politi JRdS, Viñes F, Rodriguez JA, Illas F (2013) Phys Chem Chem Phys 15:12617

49. Janthon P, Kozlov SM, Viñes F, Limtrakul J, Illas F (2013) 9:1631

50. Blöch PE (1994) Phys Rev B: Condens Matter Mater Phys 50:17953

51. Monkhorst HJ, Pack JD (1976) Phys. Rev. B: Solid State 13:5188

52. Grimme S (2006) J Comput Chem 27:1787

53. Silvi B, Savin A (1994) Nature 371:683

54. Bader RF (1990) Atoms in Molecules: A Quantum Theory, Oxford Science, Oxford, U.K

55. Henkelman G, Jónsson H (2000) J Chem Phys 113:9978

56. Henkelman G, Uberuaga BP, Jónsson H (2000) J Chem Phys 113:9901

57. Feria L, Rodriguez JA, Jirsak T, Illas F (2011) J Catal 279:352

58. Frantz PP, Didziulis SV (1998) 412/413:384

59. Saint Clair TP, Oyama ST, Cox DF, Otani S, Ishizawa Y, Low RL, Fukui K, Iwasawa Y (1999) Surf Sci 426:187

60. Chen JG (1996) Chem Rev 96:1447

61. Senanayake SD, Evans J, Agnoli S, Barrio L, Chen TL, Hrbek J, Rodriguez JA (2011) Top Catal 54:34

62. Rodriguez JA, Kuhn M (1995) 330:L657

63. Park JB, Graciani J, Evans J, Stacchiola D, Ma S, Liu P, Nambu A, Sanz JF, Hrbek J, Rodriguez JA (2009) Proc Natl Acad Sci 106:4975 
64. Yang Y, Evans J, Rodriguez JA, White MG, Liu P (2010) Phys Chem Chem Phys 12:9909

65. Yoshihara J, Parker SC, Schafer A, Campbell CT (1995) 31:313

66. Levy RB, Boudart M (1973) Science 181:547

67. Viñes F, Rodriguez JA, Liu P, Illas F (2008) J Catal 260:103

68. Florez E, Gomez T, Liu P, Rodriguez JA, Illas F (2010) ChemCatChem 2:1219.

69. Edamoto K, Miyazaki E, Anazawa T, Mochida A, Kato H (1992) Surf Sci 169/170:389

70. Florez E, Gomez T, Rodriguez JA, Illas F (2011) Phys Chem Chem Phys 13:6865

71. Viñes F, Sousa C, Illas F, Liu P, Rodriguez JA (2007) J Phys Chem C 111:16982

72. Viñes F, Sousa C, Illas F, Liu P, Rodriguez JA (2007) J Phys Chem C 111:1307

73. Tominaga H, Nagai M (2005) Appl Catal A: Gen 282:5

74. Viñes F, Gomes JRB, Illas F (2014) Chem Soc Rev DOI:10.1039/C3CS60421G

75. Dubois JL, Sayama K, Arakawa H (1992) Chem Lett 21:5

76. Wu SY, Ho JJ (2012) J Phys Chem C 116:13202

77. Posada-Pérez S, Viñes F, Ramirez PJ, Vidal AB, Rodriguez JA, Illas F (2014) Phys Chem Chem Phys DOI: 10.1039/c4cp01943a

78. Rodriguez JA, Clendening D, Campbell CT (1989) J Phys Chem 93:5238

79. Wang T, Li YW, Wang J, Beller M, Jiao H (2014) J Phys Chem C 118:3162

80. Rodriguez JA, Liu P, Takahashi Y, Nakamura K, Viñes F, Illas F (2010) 53:393

81. Rodriguez JA, Liu P, Viñes F, Illas F, Takahashi Y, Nakamura K (2008) Angew Chem Int Ed 120:6787

82. Gomez T, Florez E, Rodriguez JA, Illas F (2011) J Phys Chem C 115:11666 